\title{
Critical Aspects of RO Desalination: A Combination Strategy
}

by

Joseph Imbrogno ${ }^{1}$, John J. Keating IV ${ }^{1}$, James Kilduff ${ }^{2}$, and Georges Belfort ${ }^{1, *}$

${ }^{1}$ Howard P. Isermann Department of Chemical and Biological Engineering and

Center for Biotechnology and Interdisciplinary Studies, and

${ }^{2}$ Department of Civil and Environmental Engineering, Rensselaer Polytechnic Institute, NY 12180, USA

*Corresponding author: Georges Belfort <belfog@rpi.edu>

Table of Contents

Abstract.

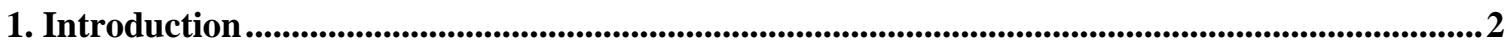

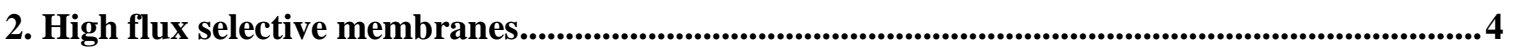

3. Types of RO Fouling ............................................................................................................................................. 6

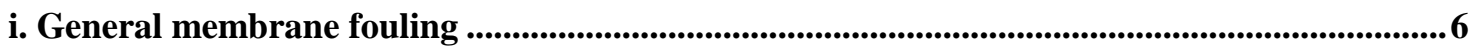

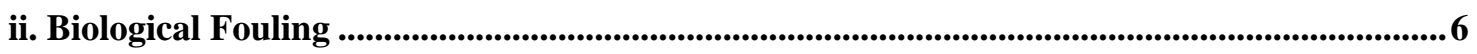

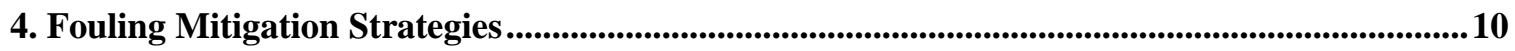

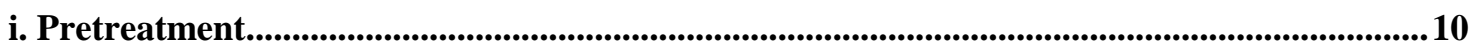

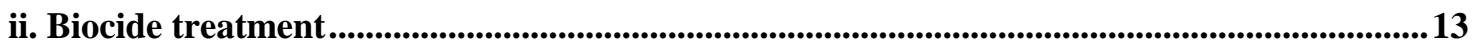

iii. Periodic cleaning ................................................................................................................................................. 14

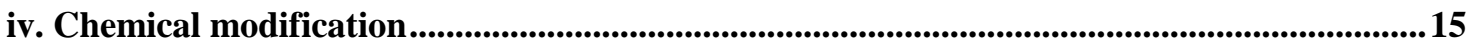

v. Fluid mechanics............................................................................................................................................17

vi. CFD modeling of spacer-filled membrane modules..........................................................................20

vii. Particle deposition...............................................................................................................................25

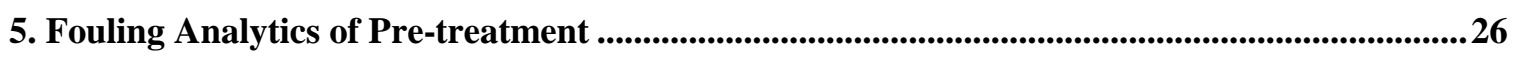

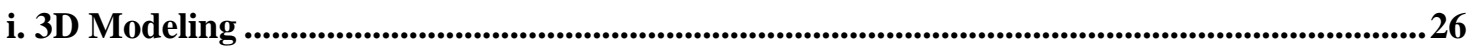

ii. Quantitative analysis and membrane performance comparison ..........................................22

iii. Fouling models and adaptation to crossflow ..............................................................................22

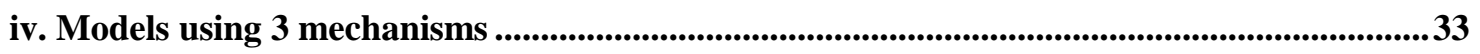

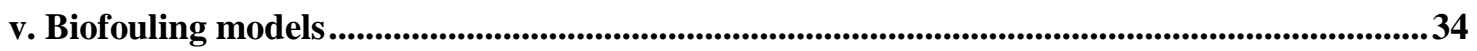

6. Post Treatment ….............................................................................................................................................................37

7. Conclusions and Future Prospects..............................................................................................

8. Acknowledgements..................................................................................................................................40

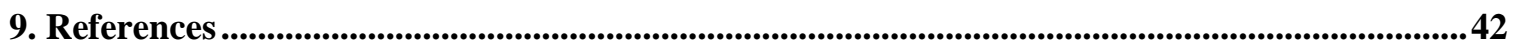




\begin{abstract}
Due to a significant drop in the energy needed for RO desalination from $12 \mathrm{kWh} / \mathrm{m}^{3}$ to 2 $\mathrm{kWh} / \mathrm{m}^{3}$ over the past 20 years, which is close to $1 \mathrm{kWh} / \mathrm{m}^{3}$, the theoretical minimum for recovering salt-free water from seawater, the focus here is on the critical aspects that offer opportunities to further reduce costs. These include pre- and post-treatment; and analysis and optimization of the performance of RO systems, such as selectivity, capacity, and flux decline. Flux decline includes concentration polarization and fouling from inorganic, organic, biological constituents. We call these the "three legs' that undergird all membrane processes. The approach here is quantitative and includes detailed fluid mechanics and associated mass transfer of RO systems for optimizing performance.
\end{abstract}

\title{
1. Introduction
}

Greater than 1 billion people worldwide lack access to potable water, and almost 2 million children die each year for lack of clean water and adequate sanitation [1]. The need for potable water is becoming acute in many places including California, Israel, the Gulf region and other arid regions, especially as global warming continues to effect climate and sea levels. Worldwide, consumption of water for municipal, industrial and agricultural uses is expected to increase substantially and aggravate this situation. Creating new sources of high-quality water through reclaiming, recycling, and reusing water will address these challenges [2].

To expand water supply, the National Academy of Engineering (NAE) recommends that engineers and scientists develop new and better ways to desalt seawater, and purify low-quality water, including brackish groundwater, storm water, grey water, and wastewater. Membrane processes offer a promising route to meet these challenges. Forty years ago, the performance of pressure-driven membrane processes yielded high salt rejection, but extremely low permeation fluxes with high energy consumption. This situation has improved markedly over the past several decades and current large scale seawater reverse osmosis (SWRO) plants are able to produce clean water for $\sim \$ 0.50 / \mathrm{m}^{3}$ [3]. Most technologies (and users) are moving away from thermal processes such as multi-stage flash and multi-effect distillation, where possible, resulting in the increased demand for faster more energy-efficient processes, such as membranes. The minimum theoretical energy required to separate $35,000 \mathrm{ppm}$ salt (seawater) at 50\% recovery is $\sim 1.06$ $\mathrm{kWh} / \mathrm{m}^{3}[4]$, while the actual energy required for the RO membrane step is now just below $\sim 2$ $\mathrm{kWh} / \mathrm{m}^{3}$.

As a result of improvements in efficiency and cost, membranes now comprise about $65 \%$ of the total global desalination capacity of $\sim 100 \mathrm{M} \mathrm{m}^{3} /$ day $[3,5,6]$, while $31 \%$ is from thermal processes. Currently, the water sources for desalination comprise seawater, surface water and saline wastewater at 59\%, 21\% and 20\%, respectively, while annual growth for desalination with membranes is $\sim 55 \%$. The total market for membrane desalination technology was $\sim \$ 30$ billion for 2015, with SWRO plants making up 50\% [7]. Although the economics of desalination has 
improved dramatically over the past three decades with improvements in energy recovery and membrane process technology [4], further efficiency gains by desalination technology and systems are needed, which will save energy and reduce environmental impact in the US and elsewhere in the future. To determine where such gains may be possible, here we consider the "three legs", or major parameters, that govern all membrane processes: (i) selectivity, (ii) permeability, and (iii) concentration polarization and fouling. Whether designing a new membrane process or choosing an existing one, one must address all "three legs".

RO performance is usually characterized first by selectivity and then by permeation flux as a function of time or accumulated volume collected (preferred) on the permeate side of the membrane [8]. Seawater $(32,000 \mathrm{ppm})$ desalination membranes require $>99.5 \%$ salt rejection in order to attain potable water standards. Other source waters (e.g., brackish groundwater) require lower salt rejection but may require greater selectivity among components (e.g., dissolved metals and boron). Once this rejection is reached, a high flux is desirable in order to render the process economical. A minimum flux of $\sim 40 \mathrm{LMH}$ ( 24 GFD) is required to meet current industry standards for desalinating seawater. Membranes with higher permeability (permeate flux/unit applied pressure), but with similar selectivity or salt rejection, are desired to reduce capital costs by lowering membrane area or operating costs by lowering applied pressure requirements.

To maintain desirable performance (salt rejection and an economically acceptable permeation flux with accumulated volume), two different mass transfer limitations have to be minimized. They include concentration polarization (CP), which is the result of the retention of non-interacting species, and membrane fouling. The interaction between $\mathrm{CP}$ and fouling is also of great concern, as each phenomenon can worsen the other. CP is caused by the accumulation of rejected salt species during RO desalination, and leads to an increase in osmotic pressure opposing the flow. The driving force for transporting essentially salt-free permeate through a membrane comprises the applied pressure minus the osmotic pressure difference between the permeate and feed. [9-11]. The magnitude of this effect is inversely proportional to the size of the species (i.e. smaller species, like ions, have a larger effect than larger species, such as colloids). Typically, RO modules are arranged in series. This requires the pressure of the feed in the first module to be greater than the osmotic pressure of the concentrate (at the brine side membrane interface) in the last module. The second mass transfer limitation is due to fouling. Fouling is the irreversible build-up of interacting species on the surface or in the membrane pores. This is considered the Achilles' heel of membrane processes because it can lead to a decrease and ultimate failure of a membrane process. Membrane fouling occurs for all pressuredriven membrane processes and negatively effects RO through organic (biofilm formation) and inorganic (mineral scaling) deposition onto and into the membrane causing performance decline with time. The value of $\sim 2 \mathrm{kWh} / \mathrm{m}^{3}$ required for desalination quoted above excludes the energy required for intake, pretreatment, post-treatment, and brine discharge - this is where many future 
cost improvements will likely take place. Thus, cost reductions in both pre- and post-treatment will be critical.

This paper investigates how the future goals for RO desalination technology and processing can be met, by reducing energy consumption; increasing permeability while maintaining desired selectivity and accounting for concentration polarization and fouling; and reducing the cost for intake, pretreatment, post-treatment, and brine discharge. In this paper, we discuss critical aspects of RO desalination, and focus on mitigating strategies of fouling and fouling analytics in RO. This approach relies on a combination strategy of membrane modification and module design (fluid mechanics), process optimization (pretreatment, periodic cleaning) and modeling. Pretreatment, cleaning and other mitigation strategies are used to address fouling and then discussed in detail. Other recent reviews have focused on fundamental transport properties [12, 13], energy requirements [14, 15], life cycle assessments [16], graphene based materials [17, 18], forward and pressure retarded osmosis [19, 20], and the overall RO process [21-23].

\section{High flux selective membranes}

Increasing permeation flux while maintaining selectivity is the holy grail of membrane science and technology [24-28]. So, it seems reasonable that new methods to form high-flux ultra-thin membranes be sought. Phase inversion and interfacial polymerization have been the dominant methods of preparing asymmetric polymer membranes for pressure-driven liquid separations for the past 40 years [29-32]. According to Kurihara [33], the interfacial polymerization method, which is widely used to prepare selective membranes and forms complex undefined rough surface morphology, needs to be replaced. Although others have recently shown that adding particles (e.g., titanium oxide, silver or zeolites) to a casting solution during interfacial polymerization can increase separation efficiency [34-37], none of these approaches, to our knowledge, have smoothed the surface on a molecular scale. Livingston et al. recently reported the successful addition of metal organic frameworks (MOFs) and nanoparticles (NPs) to synthetic membranes, an active area of chemistry and materials research [38].

If nature has optimized desalination, then we should learn nature's rules on how the aquaporin channel transports water selectively across the biological membrane. It comprises a $\sim 3 \AA$ diameter channel with mostly hydrophobic amino acids lining the walls [39]. Recent calculations show that desalination is possible at $\sim 7 \AA$ in hydrophobic channels like carbon nanotubes [40]. Conceptually, water flows through carbon or hydrophobic tubes with little or no resistance since water does not hydrogen bond to the walls [41]. Others have suggested that graphene, which is one atom thick, will offer the highest permeation flux possible for a desalination barrier when punched with 3-7 $\AA$ holes [42]. When oxidized to graphene oxide (GO) and laid as flakes onto each other on a porous support, it was shown that the tortuous paths exhibited extremely high water transport rates [43]. 
In Fig. 1, the current state-of-the-art of hydrophilic commercial and hydrophobic laboratory membrane performances are summarized. The former exhibits excellent selectivity ( $>98 \%$ salt rejection) with relatively low permeability $\left(2 \times 10^{-12}-5 \times 10^{-12}\right.$ for seawater and $6 \times 10^{-12}$ $-2 \times 10^{-11} \mathrm{~m} \mathrm{~Pa}^{-1} \mathrm{~s}^{-1}$ for brackish water), while the latter shows very high permeability $\left(2 \times 10^{-10} \mathrm{~m}\right.$ $\mathrm{Pa}^{-1} \mathrm{~s}^{-1}$ ) with poor selectivity (50-60\% salt rejection).

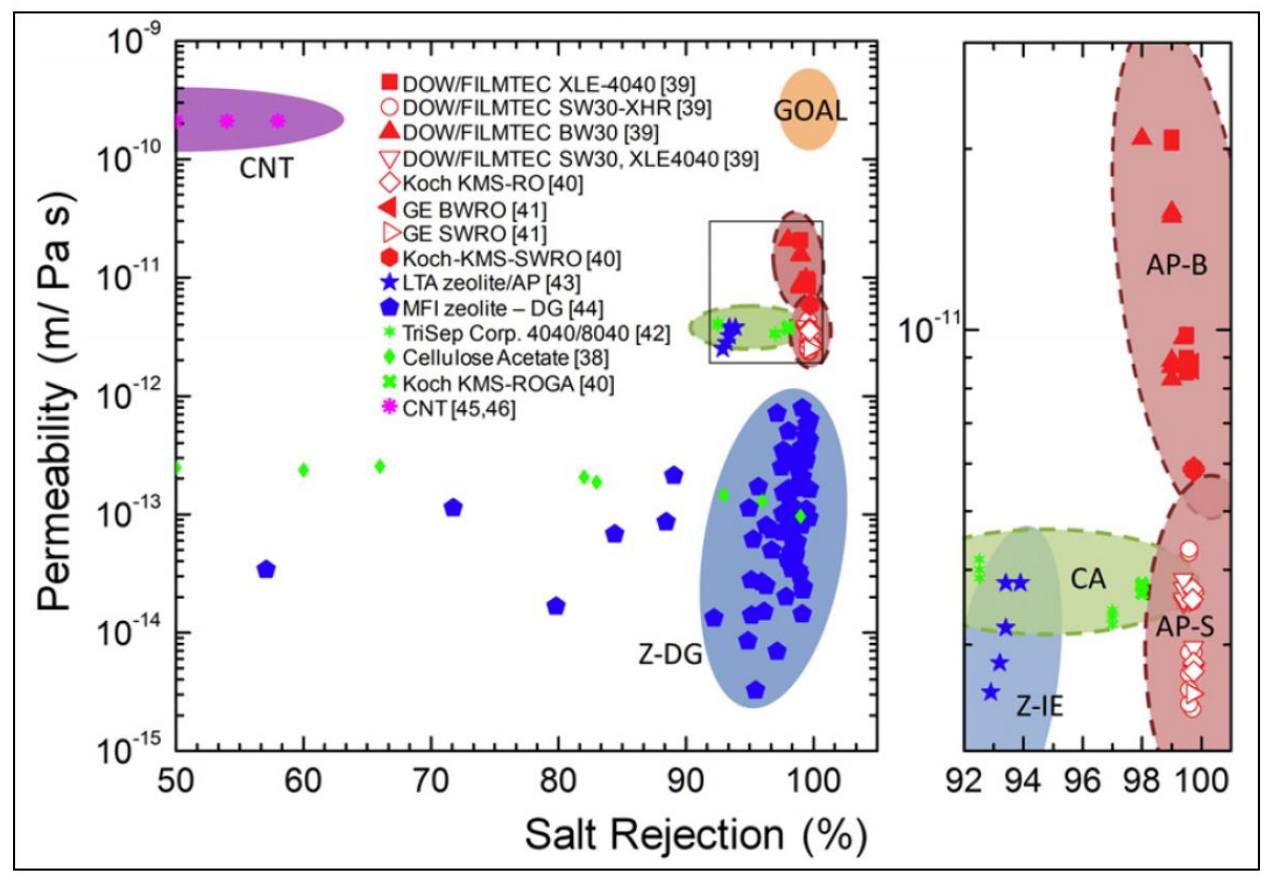

Fig. 1. Comparison of permeability and salt rejection of commercial RO membranes and nanostructured membranes reported in literature. Open symbols represent seawater/high salinity conditions while closed symbols represent brackish/low salinity conditions. Regions enclosed by dashed lines represent commercially available membranes. AP-B: aromatic polyamide (brackish); AP-S: aromatic polyamide (seawater); CA: cellulose acetate (brackish); CNT: carbon nanotube (brackish); Z-DG: zeolite, direct growth method (brackish); Z-IE: zeolite, interfacially embedded (brackish). The ideal RO membrane characteristics are indicated by the orange region (goal). A magnified view of the outlined box is shown to the right. Used with permission from Humplik et al., 2011 [23].

It is important to consider the implications of membrane surface chemistry and flux on membrane fouling. Hydrophobic membranes appear to offer high permeability, but may not sustain initially high values in the presence of organics in the feed that have high affinity for such surfaces. This is in contrast to more hydrophilic membranes, which generally exhibit less severe organic fouling. High flux membranes will inevitably lead to increased concentration polarization and fouling, which will ultimately limit the process. This is an example of how one must achieve a balance among the performance of all "three legs" of synthetic pressure driven membrane processes to achieve optimized membrane filtration and successful implementation at industrial scale. 


\section{Types of RO Fouling}

\section{i. General membrane fouling}

Flux decline occurs during membrane filtration because species in the feed stream are rejected and accumulate on (or in) the membrane as filtration proceeds. As previously discussed, flux decline can occur as a result of concentration polarization phenomena through osmotic effects, which is reversible, and can be reduced by decreasing flux, increasing mass transfer thereby reducing the build-up of solute near the membrane, or both. In contrast, fouling phenomena involves physical and chemical interactions between the feed components and the membrane surface, which may lead to adsorption or adhesion. Such fouling is difficult to eliminate, but may be minimized by pretreatment to remove foulants from the feed; judicious selection or design of membrane properties (hydrophobicity, charge density, surface roughness); control of solution $\mathrm{pH}$, ionic strength and hardness; and optimization of fluid mechanics including solution flux and surface shear. Restoring flux after fouling often requires cleaning with chemicals (acids, bases, detergents), and in some cases it may be irreversible.

The impact of fouling and the ability to restore flux depends in part on whether the foulant species are sufficiently small to penetrate into the pore structure, in part because the surface area within the porous structure can be much greater than the area of the membrane-feed interface (top face of the membrane), and because interactions with the porous support may be different. For example, Robertson and Zydney [44] found that albumin uptake in the substructure and matrix of asymmetric ultrafiltration membranes caused greater reduction in hydraulic permeability when the membrane molecular weight cutoff (MWCO) was large, because protein could gain access to the porous structure and sorption reached monolayer coverage.

\section{ii. Biological Fouling}

Mechanisms. Biological fouling was defined by Matin et al. [45] as the unwanted deposition and growth of biofilms. IUPAC defines biofilms as an "aggregate of microorganisms in which cells that are frequently embedded within a self-produced matrix of extracellular polymeric substance (EPS) adhere to each other and/or to a surface" [46]. EPS is composed of extracellular biopolymers having various structural forms, rich in 10 to $30 \mathrm{kDa}$ heteropolysaccharides such as bacterial alginate [47]. Biofouling can increase transmembrane resistance, increase osmotic pressure due to hindered mass transfer away from the membrane surface, and increase axial friction losses and pressure drop in the feed channel, due to membrane fouling, spacer fouling, or both [48].

The progression of membrane biofouling has been characterized as: 1) initial attachment of planktonic cells, during which bacteria and nutrients present in the feed solution are transported to the surface; 2) colonization of the surface and formation of a biofilm structure, and, 3) subsequent increase in pressure drop, permeate flux reduction, and deterioration of 
product quality [49]. Biofilm formation is perhaps the most problematic, as it can exacerbate pressure drop, lead to biocide resistance, and is difficult to remove, making biofouling a constant operational challenge [50].

A precursor to biofilm formation is the adsorption of humic substances, polysaccharides and proteins that "condition" the surface, changing surface properties and presenting binding sites for bacterial cells [45]. Then, bacterial cells are transported to the surface via permeation drag, where some adhere strongly, possibly as an adaptive response to low nutrient availability [51]. Subsequent EPS production, stimulated by cell-to-cell signaling, stress, or limited nutrient availability, physically stabilizes the bacterial community, forming a three-dimensional matrix that is often irreversible [51]. Finally, as the biofilm ages and is subjected to shear forces, portions of it may detach [52].

The biofilm that initially forms in feed channels and on membrane surfaces creates a hydraulic resistance that depends on biofilm composition, with EPS considered a major contributor to flux decline [49]. The volume of bacterial cells within a biofilm may be quite small; Dreszer et al. [48] reported a value of less than $0.5 \%$ of the biofilm volume. Biofilm composition may change in response to nutrients, temperature, redox potential, $\mathrm{pH}$, age, and cleaning history $[53,54]$. Since they can affect mass transfer, biofilms can promote precipitation of inorganics in systems that would otherwise be understaurated [53]. McDonogh et al. [55] reported that various cleaners could change the permeability of biofilms, in some cases increasing it by a factor of 8 without removing a significant portion of the biomass.

Desalination membrane modules are typically designed using either spiral-wound or hollow fiber configurations [56]; Khan et al. [54] report that cellulose triacetate membranes are available as fine hollow fibers. For both configurations, increased feed channel and transmembrane pressure drop and decreased salt rejection are potential indicators of biofouling [45]. Dreszer et al. [48] measured biofilm resistance of $6 \times 10^{12} \mathrm{~m}^{-1}$ in short term $(4 \mathrm{~d})$ experiments employing transmembrane flux of $20 \mathrm{~L} \mathrm{~m}^{-2} \mathrm{~h}^{-1}$; this resistance is relatively small compared with the typical resistance of NF $\left(2 \times 10^{13} \mathrm{~m}^{-1}\right)$ and RO $\left(9 \times 10^{13} \mathrm{~m}^{-1}\right)$ membranes. The biofilm resistance was about an order of magnitude higher $\left(5 \times 10^{13} \mathrm{~m}^{-1}\right)$, approaching that of RO membranes, when the transmembrane flux increased to $100 \mathrm{~L} \mathrm{~m}^{-2} \mathrm{~h}^{-1}$. This resistance has been explained by a gel-like diffusion layer [49] or a tortuous matrix [48]. Zodrow et al. [57] found that biofilms formed during desalination of Long Island Sound seawater pretreated by microfiltration. The biofilms, which consisted of a homogeneous microbial mat, caused a 5 to $7 \%$ decline in transmembrane flux over the course of the 4-d experiment; greater fouling was seen in colder weather, possibly due to greater EPS formation. A strong selection away from the bacteria naturally abundant in the seawater was observed; however, bacteria concentrations were stable, indicating succession. At high RO pressures, biofilm compression may also be important. 
Vrouwenvelder et al. [58] examined biofouling of RO and NF membranes filtering groundwater pretreated with UF. They concluded that biofouling is mainly a feed spacer channel problem, because although the feed channel pressure drop increased substantially, the transmembrane pressure drop was relatively constant over $146 \mathrm{~d}$. Consistent with the work of Dreszer et al. [48], the biofilm resistance was small compared to NF and RO membrane resistance. The increase in feed channel pressure drop, biomass ATP, and transmembrane pressure drop did not depend on whether there was permeate production $\left(J_{v}=20 \mathrm{~L} \mathrm{~m}^{-2} \mathrm{~h}^{-1}\right)$ or $\operatorname{not}\left(J_{v}=0\right)$.

Role of anti-scalants. Antiscalants are used to inhibit the formation and precipitation of crystallized mineral salts. Most antiscalants are proprietary polymers or mixtures of polymers made from polyacrylic acids, polymaleic acids, organophosphates, polyphosphates, phosphonates, or other anionic polymers. The molecular weight of antiscalants is reported to range from 2 to $10 \mathrm{kDa}$. Anti-scalants used during pretreatment can introduce nutrients and substrate that promote biofouling [59]. Vrouwenvelder et al. [60] found that biofouling in pilot scale RO modules correlated with the ATP production of bacteria grown in batch tests using anti-scalant polymers as substrate. Biofouling also correlated with the organic carbon content of the anti-scalants that could be used by microbes as substrate (the assimilable organic carbon, AOC) even though the AOC values (4 to $112 \mu \mathrm{g} \mathrm{C/l}$ ) were small, and significantly lower than the background dissolved organic carbon content (on the order of a few $\mathrm{mg} / \mathrm{L}$ ). Therefore, they recommend anti-scalants having negligible AOC values.

Sweity et al. [61] found that polyacrylate-based anti-scalants promoted biofouling by altering the hydrophobicity and surface charge of RO membrane surfaces. Polyphosphonatebased anti-scalants also contributed to biofouling by providing a source of phosphorous in otherwise phosphorous-limited conditions typical in seawater desalination [61]. More recently, the effects of different anti-scalants during brackish water desalination were investigated using microscopy techniques. Contact angle measurements increased from $21 \pm 5.8^{\circ}$ for a pristine membrane to $48 \pm 4.9^{\circ}$ and $49 \pm 1.3^{\circ}$ after addition of polyacrylate and polyphosphonate-based anti-scalants, respectively. The initial rate of flux decline during brackish water desalination was similar for both types of anti-scalants, but eventually reached a 30\% lower permeate flux for polyacrylate-based anti-scalants [61]. Addition of a polyphosphonate-based anti-scalant showed higher uptake rates of oxygen, nitrogen and phosphorous but a smaller effect on salt rejection when compared to polyacrylate-based anti-scalant. A pilot-scale study showed larger amounts of EPS on fouled membrane samples that received dosages of polyacrylate-based anti-scalant, attributed to the nutritional stress given by phosphorous-limiting conditions that in turn lead to more EPS secretion. This stress behavior was further confirmed with confocal laser scanning microscopy (CLSM) and SEM images that show a thicker biofilm on the surface of membranes supplemented with polyacrylate-based anti-scalants. As a result, polyacrylate-based anti-scalants resulted in higher flux decline effects and more pronounced bacterial adhesion rates than 
polyphosphonate anti-scalants. The use of anti-scalants in NF and RO processes is essential to prevent membrane deterioration and achieve optimal operating conditions. However, their use should be controlled and monitored to minimize biofouling effects; research is needed to develop alternatives that promote stable membrane performance [62].

Diagnosis of biofouling. There are two main goals for quantifying biofouling: (1) early detection for prevention of irreversible biofouling and (2) assessing post-mortem extent of biofouling to create fouling models for prediction and prevention. In either case, biological parameters of feed water are quantified by microbial analysis, which includes heterotrophic plate counts, total direct cell counts, ATP concentration, and assimilable organic carbon (AOC) concentration. When early detection is the goal, non-disruptive, and inexpensive measurement techniques can be used in the field to help assess whether a membrane needs to be cleaned to prevent irreversible fouling. Normalized Pressure Drop (NPD) is a widely used indicator to monitor fouling, by tracking the pressure needed to maintain constant flux operation, and defining a threshold to indicate when cleaning is needed to avoid operational problems [63]. However, NPD lacks the specificity needed to differentiate biofouling from other fouling sources, and is relatively insensitive to the onset of irreversible fouling.

Another non-invasive method uses the membrane fouling simulator (MFS) [64]. MFSs are small membrane cells equipped with a sensor for sensitive monitoring of pressure drop, and with a glass window that allows non-destructive visual monitoring. The membrane can be removed from the cell for destructive membrane testing and to obtain information about the physical and chemical characteristics of the biofouling layer [63]. MFSs have been used to measure biofilm oxygen consumption and conduct real time fluorescence imaging [65]. They have also been used to evaluate different pressure drop detectors [66]. MFSs are limited in that they only monitor feed channel pressure drop; however, these devices hold promise to help optimize cleaning strategies in NF and RO membranes.

Assessing biofouling at a level of detail sufficient to support model development requires examining the behavior and distribution of microbes on the surface of the membrane. Indirect measurements of biological activity include uptake of substrate, oxygen, nitrogen and phosphorus. Bacteria can be imaged with electron microscopy, and fluorescent staining in combination with confocal laser scanning microscopy and in-situ hybridization can localize type of microbes on surfaces and distribution of polysaccharides, lipids, and proteins. Data from such experiments can help elucidate mechanisms and key players in biofouling, which can inform models for biofilm growth. Such models can be helpful to identify and test methods to inhibit biofilm growth. The goal is to develop techniques to monitor membrane biofouling in real time, non-destructively, in- situ, accurately and reproducibly to track factors that promote biofilm growth [67]. 


\section{Fouling Mitigation Strategies}

\section{i. Pretreatment}

Pretreatment is a critically important step in effective desalination of seawater. It also offers the opportunity to reduce the total production cost of desalinated water. The raw seawater feed must first be treated in order to remove a large extent of the foulants before reaching the RO membrane. Physical pretreatment, including conventional filtration and MF/UF, can be used to reduce fouling, silt density index, and turbidity of the feed seawater. Physical pretreatment includes filtration through screens, sedimentation, cartridge filters, sand filters, and MF/UF membrane filtration [68]. Chemical pretreatment is also commonly used to reduce scale formation and coagulants as well as disinfect the water. Chemical pretreatment uses additional chemicals such as $\mathrm{FeCl}_{3}$ and $\mathrm{FeSO}_{4}$ as coagulants in addition to disinfectants and anti-scaling agents [77, 88]. Chemical pretreatment has proven to be effective; however, since chemicals are being introduced into the feed stream, they must be removed later on in the process. It is undesirable to add new species to the feed stream if possible, although some plants combine physical and chemical pretreatment. Several factors are involved when choosing the appropriate type of pretreatment. These include quality and consistency of the feed seawater, capacity of the system and available footprint for the equipment, cleaning and maintenance costs, and capital and operating costs [69]. Pretreatment steps are dependent upon the quality of the seawater, except for UF which is largely independent of the incoming water quality [70]. The methods currently employed have not changed much over the years, so newer technologies are needed. Desirable improvements include longer lifetime of UF membranes, alternative technologies that require lower pressure, and better chemical treatment options.

Physical pretreatment is less expensive than traditional chemical pretreatment since no additional chemicals need to be added, this includes the additional costs of the UF membranes [71]. Hollow fiber UF technology has increasingly gained acceptance as a viable alternative for seawater pretreatment [72-74]. Reasons for the increasing interest in UF pretreatment over conventional approaches include superior and more consistent filtrate water quality, ability to cope with variable feed water quality, lower plant footprint, and competitive cost [72]. UF membranes with a pore size of $0.02 \mu \mathrm{m}$ have been the most effective for removing silt, algae, bacteria, and large molecular weight organics [70]. For example, Hong et al. [74] demonstrated that the UF pretreatment achieved 1.96-log removal of bacterial cells. The permeate stream must have a turbidity below $0.1 \mathrm{NTU}$ and a $15 \mathrm{~min}$. silt density index $\left(\mathrm{SDI}_{15}\right)$ less than 2.5 [70]. The $\mathrm{SDI}_{15}$ is measured by monitoring the flux decline over $15 \mathrm{~min}$. when the feed is continuously filtered through a $0.45 \mu \mathrm{m}$ membrane at a TMP of $30 \mathrm{psi}$. UF is able to achieve an SDI less than 1 starting from a feed with an $\mathrm{SDI}_{15}$ of $13-25$, whereas conventional pretreatment is unable to reach below 2.5 [75]. Reducing the SDI further below 2.5 is not required, but the lower the SDI the lower the frequency of cleaning of the RO membrane. Conventional pretreatment involves coagulation and a two stage sand filtration, which requires the RO membrane be cleaned 4-12 
times per year [76]. Typical lifetime of this system is $20-30$ years. Using UF, the RO cleaning frequency is only 1-2 times per year. Typical lifetime of the UF membranes is 5-10 years [77]. An advantage of UF is that it is relatively independent of the feed water composition [70]. In order to prevent the UF membrane from being damaged, a fine screen of 80-120 $\mu \mathrm{m}$ must be used before the UF step $[78,79]$. This will prevent tearing or other damage to the membrane from glass, shells, or other contaminants.

There are several other unique advantages to UF pretreatment. UF membranes are reliable and have been shown to maintain permeate turbidity over at least six months, even with high turbidity feed water [80-82]. They also have a small footprint and remove the cost of additional chemicals and disposal of those chemicals as hazardous waste. For instance, coagulants, such as ferric chloride, are no longer needed and the RO membrane cleaning frequency is reduced [78]. UF membranes require lower energy [84] and they reduce the environmental impact of the process by more than $30 \%$ since they have a smaller footprint, require fewer materials, and have low energy consumption [70, 85]. UF membranes are better at removing solids and are simpler to operate than chemical pretreatment methods. These membranes can also be embedded with metal nanoparticles, such as $\mathrm{TiO}_{2}$, to increase their antibiofouling effects $[86,87]$. These membranes are typically made of stable polymers with high glass transition temperatures, such as poly(ether sulfone) (PES) or polysulfone (PSf). A process diagram of traditional UF pre-treatment is shown in Fig. 2 [83]; for purposes of illustration, several examples will serve to illustrate important operational details.

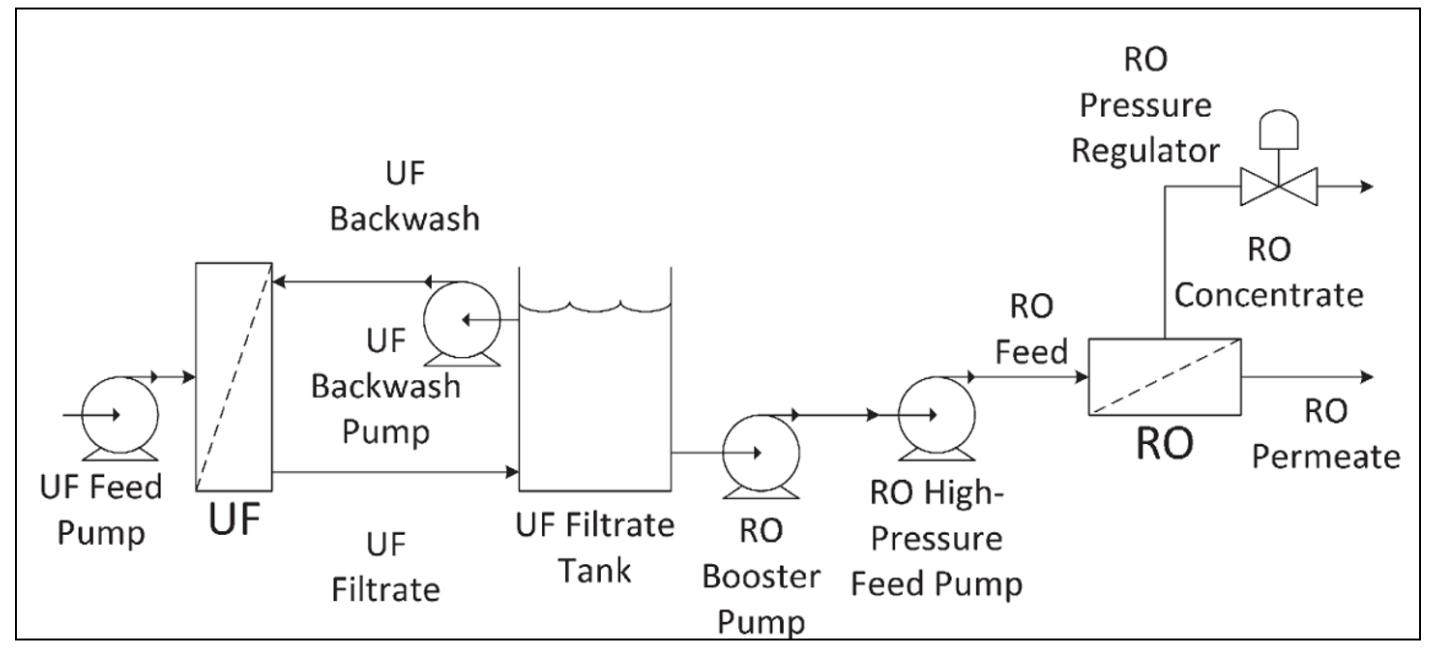

Fig. 2. Process diagram of a conventional integrated UF-RO system design that utilizes an intermediate UF filtrate storage tank for UF backwash water, UF backwash pump, and RO booster pump. Used with permission from Gao et al., 2016 [83].

The Maspalomas-I Desalination Plant, located in the island of Gran Canaria, Spain, produces $14,500 \mathrm{~m}^{3} / \mathrm{d}$. Hollow fiber PVDF UF membranes (Dow $0.03 \mu \mathrm{m}$ pore size) are used for RO pretreatment [3]. The UF system operates in dead-end mode at fluxes ranging from $65-80$ 
LMH, depending on demand, with 60 min filtration cycles before backwashing with ultrafiltrate water. Air scour at the feed side of the fibers aids backwashing. Chemically enhanced backwash (CEB) is carried out using $200 \mathrm{mg} / \mathrm{L}$ sodium hypochlorite at intervals of 24 to $48 \mathrm{~h}$ for organic fouling control and disinfection. Hong et al. [3] found that CEB removed sulfate-reducing bacteria from UF membranes, preventing sulfate reduction and hydrogen sulfide production by Pseudomonas in coexistence with Desulfovibrio, thus mitigating corrosion problems and ensuring membrane integrity. An acid CEB with $\mathrm{HCl}$ at $\mathrm{pH} 2.0$ to 2.2 is executed every $72 \mathrm{~h}$ as maintenance cleaning to prevent inorganic scale accumulation. In addition, the plant has capability for offline intensive cleaning via a clean in place (CIP) system using heated RO permeate; however, this has not been needed after almost one year of operation. To minimize the chlorine residual downstream of the UF membranes, a thorough rinse via backwash is carried out after CEB, and the initial ultrafiltrate volume after rinsing is wasted to drain until the residual chlorine is below $0.20 \mathrm{ppm}$. In addition, sodium bisulfite (SBS) is dosed temporarily at the UF product tank inlet. Sodium bisulfite dosing at the RO feed is also done after disinfection of the UF product tank.

The Adelaide Desalination plant has a 30,000 m³/d capacity, and employs Memcor submerged PVDF UF membranes for RO pretreatment. Membranes operated at a flux of 53 LMH during pilot testing, and 44 LMH during commissioning. Dixon et al. [1] describe UF cleaning trials at pilot scale and full scale commissioning at 1/10 capacity. The system design incorporates a UF product tank, and cartridge filters downstream of the feed tank and directly upstream of the RO membranes. Optimization of the UF cleaning regime included intake disinfection (shock dosing), maintenance washes, and CIP protocols to reduce energy and chemical consumption. The design UF backwashing interval was $30 \mathrm{~min}$, but it found that a 70 min interval was sufficient. Shock dosing of the feed using $15 \mathrm{mg} / \mathrm{L}$ sodium hypochlorite was found to be an effective tool to control biogrowth in the UF system. Maintenance washes to control biological accumulation consisted of dosing $300 \mathrm{mg} / \mathrm{L}$ sodium hypochlorite at 4-d intervals. Less frequent (two week intervals) washes with sulfuric acid (pH 2 to 4) were also recommended. A two-stage CIP protocol consisted of $4 \mathrm{hr}$ soak and filtration cycles using $500 \mathrm{mg} / \mathrm{L}$ sodium hypochlorite followed by $0.25 \%$ citric acid, adjusted to $\mathrm{pH} 2.0$ using sulfuric acid. The authors recommend a heating system heating to ensure a cleaning recirculation temperature range of $20-25^{\circ} \mathrm{C}$, but did not recommend a specific interval for this protocol. Sodium metabisulfite was used to neutralize free chlorine residual prior to the RO to prevent membrane oxidation. The best placement of the metabisulfite feed was directly upstream of the RO membranes, and downstream of the cartridge filters, to include the cartridge filtration in the shock chlorination pathway.

Cohen et al. have made several recent advancements in this field by directly integrating the UF and RO steps, without using an intermediate filtrate storage tank, and backwashing the UF membranes with the RO concentrate [83]. A schematic of this process is shown in Fig. 3 [83]. 


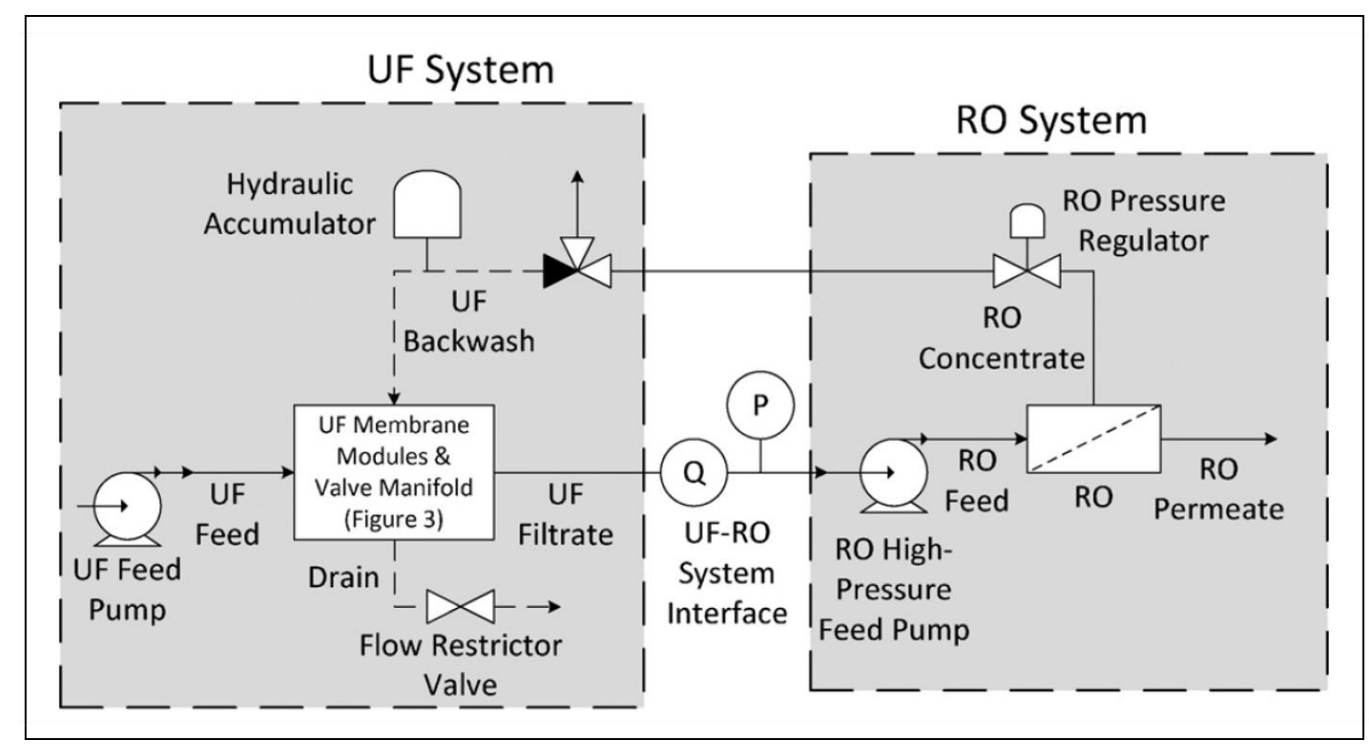

Fig. 3. Process diagram of a directly integrated UF-RO system. Flow rate $(\mathrm{Q})$ and pressure $(\mathrm{P})$ at the UF-RO system interface are maintained by a control system. Used with permission from Gao et al., 2016 [83].

Both physical and chemical pretreatment have drawbacks. UF pretreatment includes cleaning costs, replacement membranes, and cartridge disposal. The waste is typically sent for land disposal. Cleaning, disposal, and replacement of membrane cartridges increases the cost to make the product water [77]. In fact, the cleaning cost of the UF membranes is more than the cleaning cost for the RO membranes [89]. Chemical pretreatment includes pre-treated sludge disposal, high chemical usage, and sludge production. The waste is typically deposited into a landfill. Transportation of the sludge represents $18.4 \%$ and disposal represents $78.3 \%$ of the cost of sludge removal, increasing capital costs by up to $25 \%$ [77]. Therefore, reducing the amount of sludge produced would significantly reduce the costs associated with chemical pretreatment. The areas that require the most improvement in the pretreatment process are corrosion of piping and other equipment, brine and sludge concentrate disposal, and boron and bromide level management in the water [77].

\section{ii. Biocide treatment}

The use of chlorine as a biocide is not always successful and in some cases has been known to worsen biofouling [53]. It is possible that chlorine promotes EPS formation by stressed organisms that survive the treatment, and those that do not survive may serve as a nutrient source for remaining organisms. In addition, chlorine may oxidize other organics (such as humic substances), making them more bioavailable as a carbon source [53]. Kahn et al. [54] demonstrated that chlorination could not prevent biofouling of hollow fiber SWRO membranes and concluded that chlorine failed to access all regions of the modules. They also cited the possibility that bacterial populations developed resistance to chlorine over time. 


\section{iii. Periodic cleaning}

Another method used to mitigate fouling is periodic cleaning of the membranes. Clearly there is a trade-off between cleaning intensity and frequency and pretreatment. Since all membranes will inevitably foul, they usually need to be cleaned periodically. Membranes are typically cleaned when their performance falls below a certain threshold, usually after a decrease in permeate flux of $10 \%$ or a pressure increase of $15-20 \%$ [90, 91]. Cleaning represents approximately $5-20 \%$ of the overall cost of the RO process [92]. There are three different types of cleaning methods: physical, chemical, and biological. Of these, chemical cleaning methods are the most common. The chemicals used are chosen based on the membrane material and the solubility of the foulants. Additionally, the water used in the cleaning process must be of high quality, in order to avoid introducing more foulants into the system [93]. High quality water should be used, but additives such as ethylene diamine tetra-acetic acid (EDTA) and polyphosphates can also be used to increase the solubility of metal ions that are present on the membrane (Ca, Mg, Mn, Fe) [94]. These impurities can reduce the cleaning efficiency, especially chlorine. Species such as sodium, nitrates, and sulfates have been shown to increase the efficiency of the process (flux recovery) [93]. Common strategies for cleaning membranes include: $0.1 \mathrm{M}$ sodium hypochlorite at $50^{\circ} \mathrm{C}$ for $30-60 \mathrm{~min}$. (not compatible with stainless steel equipment over long periods), $0.1-0.5 \mathrm{M} \mathrm{NaOH}$ at $50^{\circ} \mathrm{C}$ for 30-60 min. (store membranes in 0.1 $\mathrm{M} \mathrm{NaOH}$ ), $0.1 \mathrm{M}$ phosphoric acid at $50^{\circ} \mathrm{C}$ for $30-60 \mathrm{~min}$. (used to dissolve residual minerals that may plug pores), and $1 \mathrm{M}$ salt solutions $(\mathrm{NaCl})$ for 30-60 min. (decreases the Debye length around proteins and the membrane surface causing the proteins to lift off the surface due to reduced electrostatic interactions) [95]. When choosing a cleaning method, there are several parameters to consider, such as $\mathrm{pH}$, concentration, washing time, crossflow velocity, pressure, temperature, and chemical [96-98]. Physical methods, such as backpulsing have also been successful in cleaning the membranes after fouling [99-101].

Biofilm formation is particularly difficult to remove and is usually cleaned using a twostep process. First, the biofilm matrix is weakened using chemicals that interfere with bonding and second, shear forces are used to remove the biofilm from the surface [102]. Commonly used chemicals include alkalis, acids, metal chelating agents, surfactants, oxidation agents, and enzymes [103, 104]. For spiral wound cellulose acetate RO membranes, enzyme anti-precipitantdispersants and bacterial agents with an anionic detergent were found to be the most effective ways to remove biofilms $[105,106]$.

The pore structure of the membranes is often altered due to fouling. In a paper by Roth et al. these changes were monitored by tracking salt concentration [107]. Before fouling, the salt concentration distribution was unimodal, but after fouling it was multimodal. It is believed that these effects could be due to an enlarged pore size. Additionally, chlorine is able to degrade many different types of membranes and therefore should be minimized or removed before reaching the membranes. The $\mathrm{RO}$ membranes are sometimes made of cellulose acetate, which 
can be degraded by chlorine ions. One way to counter this is to add ammonia to the feed, forming ammonium chloride [108]. For polyamide membranes, chelating agents and surfactants with alkali were able to clean the membranes better than just acids and alkalis alone [106].

Backpulsing, reversing the flow direction, can be used to help dislodge foulants and increase the time between cleaning; it is also an effective method for reducing biofilm formation. Results have shown that backpulsing can increase the net flux by two-fold and four-fold for 0.2 $\mu \mathrm{m}$ Anopore and cellulose acetate, respectively, when fouled with $0.05 \mathrm{~g} \mathrm{~L}^{-1}$ yeast cells [99]. However, weaker backpulses were unable to dislodge strongly bound foulants and increasing the duration of the pulses only lead to an increase in fluid loss. Semi-empirical modeling the effectiveness of back-pulsing is also available [101].

\section{iv. Chemical modification}

Chemical modification of the UF and RO membranes is also an effective method for mitigating fouling. Current modification techniques include polymer grafting by chemical treatment (UV and plasma), thin-film coating, and layer-by-layer assembly. Belfort et al. have developed a high throughput screening platform that utilizes free radical polymerization to graft and screen hundreds of different surfaces per day [109-113]. Radicals can be induced on PES membranes using UV light (no initiator required) or atmospheric pressure plasma, thereby activating them and allowing them to react with a library of many different monomers each containing different functional groups and properties. One is able to vary the grafting density, monomer concentration, plasma power, exposure time, plasma distance from sample, and residence time of the plasma exposure. This method is also amenable to grafting newly synthesized monomers and screening them for the best performing modification. This allows one to tune the surface chemistry for a specific process or a specific step of a process. PEGs, zwitterions, amides, and amines have been shown to be anti-protein fouling, which can be useful for the UF pretreatment step to prevent biofilm formation due to polysaccharide and protein secretions. In particular, ( $\mathrm{N}$-isopropylacrylamide), diacetone acrylamide, 2-(dimethylamino) ethyl methacrylate) exhibited protein resistance [114]. This will increase the lifetime of the UF membranes and increase the time between cleaning. This platform was developed for UF PES membranes, but has been applied to MF and NF membranes as well and can be applied to RO.

Since polyamide membranes are typically negatively charged due to unreacted carboxylic and amino groups present on the surface, this leaves them open for reaction or non-covalent attachment, such as surface coating. Surface coating is typically a two-step process, first the membrane is soaked in a polymer coating solution and then the solvent is evaporated leaving a thin coating layer [115]. The membranes can be coated with various different polymers, such as PEG, polydopamine, zwitterions, and chlorine resistant coatings, in order to increase performance during desalination. 
PEGs have long flexible chains with a large excluded volume and a repeating unit of $\left(\mathrm{CH}_{2} \mathrm{CH}_{2} \mathrm{O}\right)_{\mathrm{n}}$. PEGs have a Flory-Huggins interaction parameter of 0.4-0.5 [116]. Water molecules have been shown to create a hydration shell and lower the polymer-water interfacial energy, which reduces cell adhesion [117-119]. PEGs are known to be hydrophilic and reduce adhesion of bacteria and proteins [115]. Additionally, they can be cross-linked to form a hyper branched polymer which can prevent biofilm formation. Polydopamine coatings do not have a significant effect on permeability and can be used as an immobilization platform for covalently attaching PEG and other molecules of interest [120, 121].

Zwitterionic coatings are able to bind water more strongly than other materials due to electrostatically induced hydration $[122,123]$. Chlorine resistant coatings are extremely useful since the membranes used in RO desalination are susceptible to degradation by chlorine. Metaphenylene diamine (MPD) groups contain electron donating groups, such as $-\mathrm{CH}_{3}$ and $-\mathrm{OCH}_{3}$, that have high chlorine resistance [124-126]. Positively charged and neutral surfaces are believed to be more chlorine resistant than negatively charged surfaces. However, the addition of MPD makes the RO membranes less hydrophilic.

Layer-by-layer ( $\mathrm{LbL}$ ) assembly is another method that can be used to change the surface properties of a membrane. LbL was developed by Gero Decher and involves dipping the substrate in alternating solutions of polycations and polyanions with DI water washing in between [127, 128]. LbL assembly can use electrostatic interactions, hydrogen bonding, or covalent bonding to attach the layers to the surface. The film properties are a function of polyelectrolytes used, $\mathrm{pH}$, and deposition time. The two types of polyelectrolytes are strong (e.g. poly(diallyl dimethyl ammonium chloride) and weak (e.g. poly allylamine hydrochloride) [129132]. Since the layers are on the nanoscale in thickness, permeability is high and high charge density increases rejection [133]. Nanofiltration membranes with LbL deposition are able to retain ions for desalination $[134,135]$. They have been able to achieve up to $96 \%$ salt rejection of $\mathrm{SO}_{4}{ }^{2-}$ with $\mathrm{Cl}^{-} / \mathrm{SO}_{4}{ }^{2-}$ selectivity of $\sim 2.7$ using 60 layers of deposition, although the fluxes were very low. LbL NF membranes were also able to remove $\mathrm{F}^{-}$with high flux based on size exclusion (not charge) [136].

A study by Tieke et al. deposited 60 bilayers of polyvinyl alcohol (PVA) and polyvinyl sulfate (PVS) on a PAN/PET support and tested the assembly in a high pressure desalination test cell $[137,138]$. The results showed up to $93.5 \% \mathrm{NaCl}$ rejection at 40 bar. When a non-diluted salt system was used, $56.6 \%$ rejection at 20 bar and $74.5 \%$ rejection at 40 bar were achieved for $\mathrm{NaCl}$. Rejection for divalent ions was greater than $95 \%$ at 40 bar. These lower rejections were due to concentration polarization and the inability of these LbL membranes to achieve high rejection at high salt concentration. However, as the number of layers increased, the permeability decreased by up to 2000 times the unmodified substrate. The flux can be increased using a more porous support layer. Another study by Park et al. used PAA and PAH to form nano-thin films on a PSf support to reject saltwater with a concentration of $2000 \mathrm{ppm}$ [139]. The layers were 
cross-linked via thermal annealing at $180^{\circ} \mathrm{C}$ for $1 \mathrm{hr}$. A rejection of $81 \%$ was achieved using 20 bilayers and up to $99 \%$ rejection was achieved when the dilute permeate was recycled.

LbL deposited layers are able to reduce the flux decline over time since they are more anti-fouling and reduce concentration polarization [140,141]. This is advantageous even though the initial pressure requirement is higher than conventional RO. The biggest drawback of LbL is the added thickness, which leads to a decrease in flux by increasing the resistance. Additionally, non-covalent $\mathrm{LbL}$ attachments are likely unsuitable for water desalination applications. This is due to the fact that certain species (e.g. PEG) are water soluble and will dissolve into the feed stream over time [115]. This renders the LbL modification ineffective; therefore, covalent attachment is required. $\mathrm{LbL}$ is not able to achieve a high enough salt rejection to compete with current technology. In order to increase the rejection to current standards, either an excessive number of bilayers must be used or the layers need to be highly cross-linked. Since these changes will increase the resistance, the required operating pressure will increase. Dutta et al reported that LbL layers when neutralized become stiff and this could also affect performance [142].

\section{v. Fluid mechanics}

Introduction to the need for fluid flow: Fluid mechanics, with regard to synthetic membrane operation and performance, is intimately involved with the transport of mass of fluid and dissolved and suspended components in the fluid towards and away from the membrane. For desalination of sea- and brackish-waters by reverse osmosis (RO), water needs to be transported to the membrane so it can pass through the membrane while retaining the salt and other solutes on the feed or brine side. The difference between membrane ultrafiltration for bioprocessing and potable water reclamation with RO is that in bioprocessing the solutes, such as proteins, are the desired product. For potable water RO filtration, on the other hand, the carrier fluid (water) is the product. Consequently, pretreatment (to remove foulants) and fluid management (to control concentration polarization, $\mathrm{CP}$ ) is important for RO, while fluid management is critical for ultrafiltration since the solids are retained and desired.

Feed fluid can flow directly toward the membrane and this is called normal or "deadended" flow. It is mainly used in small laboratory applications. For large-scale laboratory and commercial plants, the feed fluid moves across or tangentially along the membrane and is called tangential or crossflow filtration. The reason for this has to do with removing part of the buildup of retained species (salt, precipitate, organics, cells and other debris) at the solution-membrane interface. Since most other solutes besides salts are mostly removed through pretreatment for RO, only $\mathrm{CP}$ and fouling of salts that precipitate like $\mathrm{CaCO}_{3}$ or silica are mainly of concern.

Laminar and turbulent crossflow: Most RO plants operate in crossflow or tangential mode in the laminar regime. The reason for this is most easily seen through the Fanning friction factor for flow in a tube of radius $R$ and length $L$. 


$$
f=\frac{-\Delta p_{t c}}{\frac{\rho}{2} \bar{u}_{0}^{2}}=\frac{\text { axial pressure drop }}{\text { kinetic energy consumption }}
$$

where $\Delta \mathrm{p}$ is the time-smoothed pressure drop down the channel of length, $\mathrm{L}$, and $\overline{\mathrm{u}}$ is the mean axial flow rate. In Fig. 4, $\mathrm{f}$ is plotted against the axial Reynolds number, $\mathrm{Re}=(2 \mathrm{UR} / \mathrm{v})$, where $v$ is the kinematic viscosity [143].

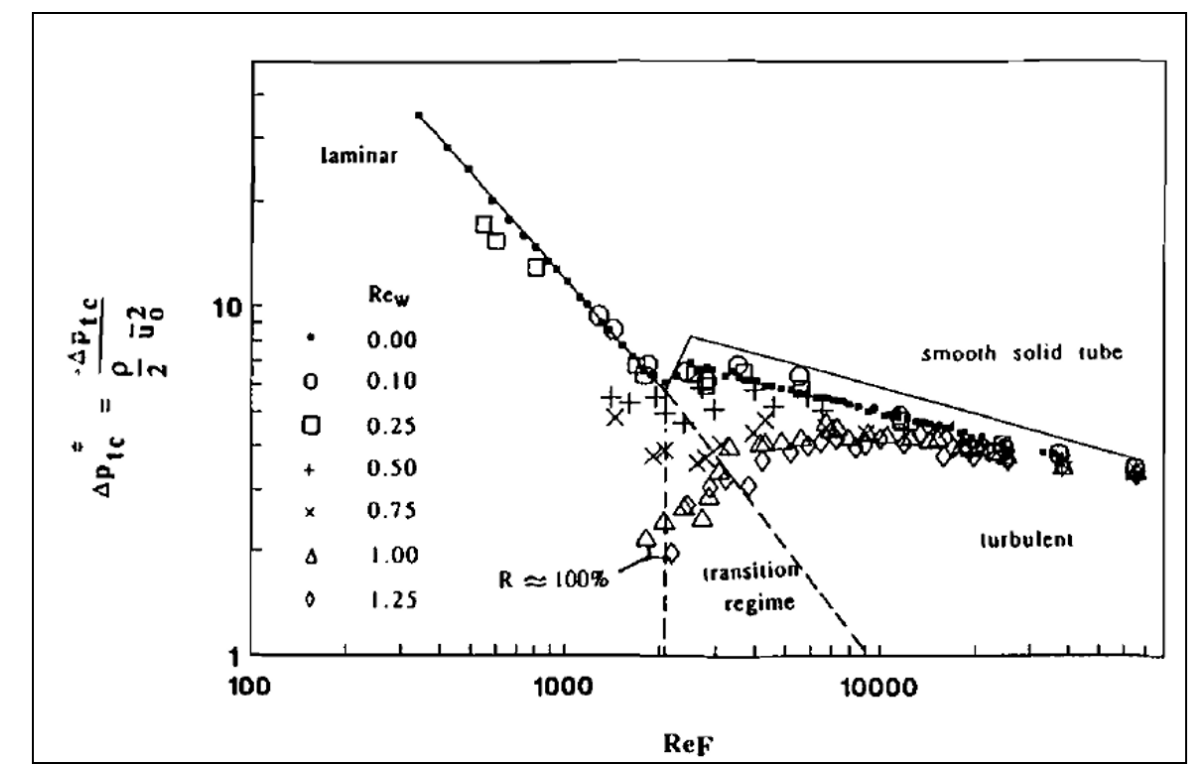

Fig. 4. Experimental dimensionless trans-cartridge pressure drop as a function of feed Reynolds number $\left(\mathrm{Re}_{\mathrm{F}}\right)$ for different wall Reynolds number $\left(\mathrm{Re}_{\mathrm{W}}\right)$. $\mathrm{R}$ is the volumetric recovery ratio. Used with permission from Mellis et al., 1993 [143].

For laminar and turbulent flow $\Delta p$ is approximately proportional to $\overline{\mathrm{u}}$ and $\overline{\mathrm{u}}^{2}$, so that $\mathrm{f} \sim$ $1 / \overline{\mathrm{u}}$ and a constant, respectively. Hence using less energy to pump the fluid across the membrane in the laminar regime is preferred in RO and other membrane systems in spite of increased mass transfer in the turbulent regime. With a permeable tube with wall flux, the effect is mostly observed in the transition and low turbulent regime and is proportional to the wall Reynolds number, $\operatorname{Re}_{\mathrm{w}}=\left(2 \mathrm{~V}_{\mathrm{w}} \mathrm{R} / \mathrm{v}\right)$, where $\mathrm{V}_{\mathrm{w}}$ is the mean permeation wall flux.

Fluid flow in membrane slits and tubes: Berman (1956) and Yuan and Finkelstein (1956) using regular perturbation methods, solved the laminar flow fields in a porous slit (2-D) and a porous tube (3-D), respectively. The latter are given below for axial, $\mathrm{u}$, and transverse, $\mathrm{v}$, velocity: 


$$
\frac{u}{u_{0}}=\left[\frac{1}{0.7854+\frac{0.8437}{\lambda}}+\frac{4 \lambda x}{R e R}\right]\left[\frac{\pi}{4} \cos \frac{\pi}{2} \eta+\frac{f_{1}^{\prime}}{\lambda}+\cdots\right]
$$

and

$$
\frac{v}{u_{0}}=-\frac{2 \lambda}{R e \sqrt{\eta}}\left[\frac{1}{2} \sin \frac{\pi}{2} \eta+\frac{1}{\lambda} f_{1}+\cdots\right]
$$

where $\lambda=\operatorname{Re}_{\mathrm{w}}, \mathrm{u}_{0}=\mathrm{u}(\mathrm{v}=0)$ and $\eta=(\mathrm{r} / \mathrm{R})^{2}$ and $\mathrm{f}_{1}$ and $\mathrm{f}_{1}$ ' are integral functions from Yuan and Finkelstein (1956). Berman's equations for flow in a slit are similar and simpler (1956).

Fluid mass balance in a membrane tube: Belfort (1981) has shown that for the tangential fluid velocity in the $\mathrm{z}$-direction and $\mathrm{r}$ as the radial coordinate measured from the center-line, $\mathrm{v}_{\mathrm{z}}(\mathrm{r}, \mathrm{z})$ (units: $\mathrm{L} / \mathrm{T}$ ), and inlet flow rate $\mathrm{Q}_{\mathrm{in}}(\mathrm{r}, \mathrm{z}=0)$ (units: $\mathrm{L}^{3} / \mathrm{T}$ ), with Poiseuille parabolic flow are given by:

$$
v_{z}(r, z)=v_{z}(0, z)\left[1-\left(\frac{r}{R}\right)^{2}\right]
$$

and

$$
Q_{\text {in }}(r, 0)=Q_{0}=Q_{\text {out }}(r, z)+Q_{\text {wall }}(R, z)
$$

where on substituting for $\mathrm{Q}_{\mathrm{wall}}=2 \pi \mathrm{Rz} \mathrm{V}_{\mathrm{w}}$ for a length in the tube of $\mathrm{z}$, and knowing that $\mathrm{v}_{\mathrm{z}}(0, \mathrm{z})=2 \mathrm{U}$, we get a mass balance for flow in equals flow out plus flow through the walls:

$$
v_{z}^{\text {max,entrance }}=v_{z}(0,0)=2 U=\frac{2 Q^{\text {exit }}}{\pi R^{2}}+\frac{4 z V_{w}}{R}
$$

Thus for the case with flow leaving the exit, the length of the tube, $z$, cannot be too large.

Particle transport in laminar flow: Particles are thought to move in laminar flow in a cross flow membrane duct via Brownian motion (B), shear induced diffusion (SID) and inertial lift (IL) (Fig. 5) [144]. Clearly, these phenomena are important for different size ranges of particles of diameter 2a. Also, increasing axial velocity or Reynolds number increases the wall 
shear rate, $\Upsilon$, and hence the permeation flux, J, to the power of $1 / 3,1$ and 2 for B, SID and IL, respectively. Increasing particle radius, a, increases the permeation flux, J, to the power of $-2 / 3$, $4 / 3$ and 3 for B, SID and IL, respectively.

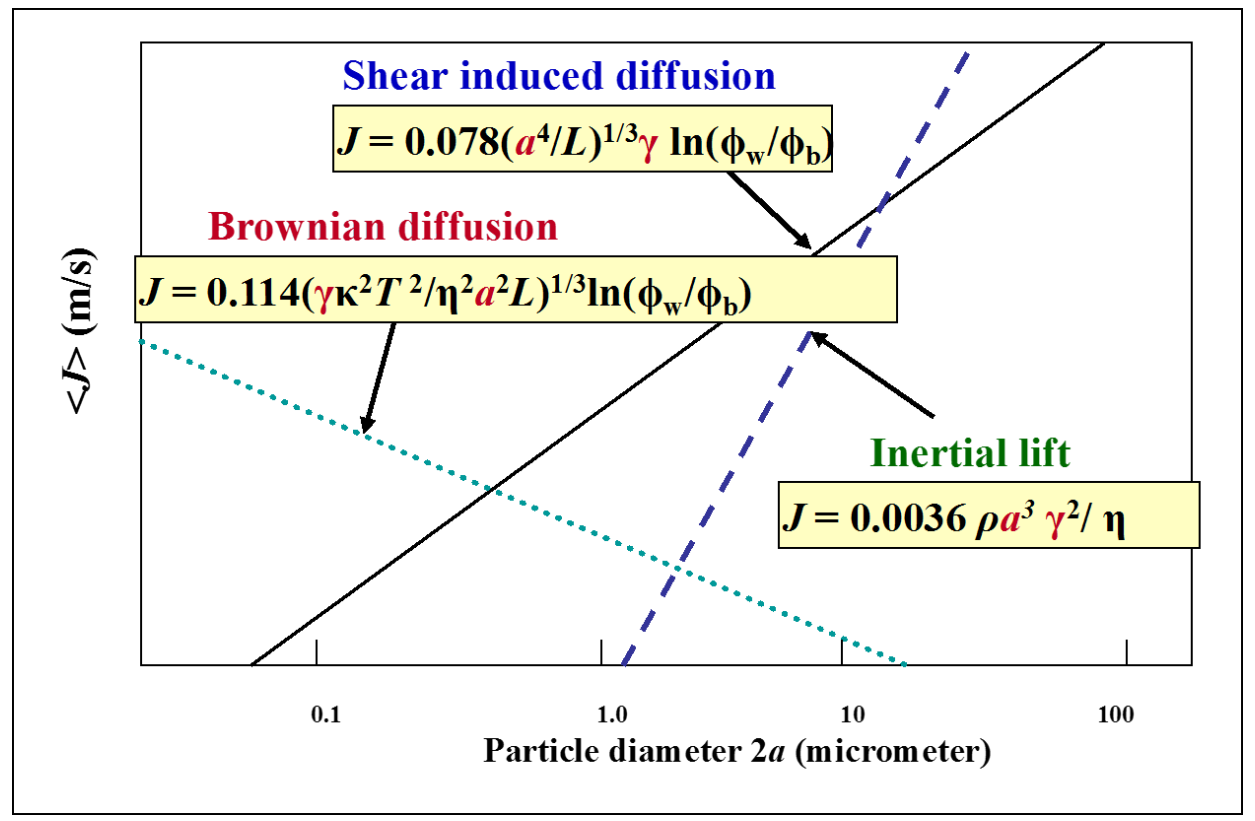

Fig. 5. Experimental dimensionless trans-cartridge pressure drop as a function of feed Reynolds number $\left(\operatorname{Re}_{\mathrm{F}}\right)$ for different wall Reynolds number $\left(\mathrm{Re}_{\mathrm{W}}\right) . \mathrm{R}$ is the volumetric recovery ratio. Adapted from Belfort et al., 1994 [144].

Self-cleaning fluid mechanics: In 1928, Dean showed that fluid flowing around a curve produces vortices in a controlled manner [145]. Belfort has adapted this technology to synthetic membranes and shown that these vortices can be used to self-clean membranes from foulants like yeast cells and debris producing permeation flux improvements of over 400\% in some cases [143, 146-153]. Advantages beside performance enhancement include scalable design, no moving parts or sealing problems, possible to backwash, no heating, no holdup on screens and easy to drain. However, more energy is needed to produce these self-cleaning vortices and this could exclude them form RO and water treatment due their low cost of product. An example is shown in Fig. 6 for yeast ultrafiltration [154].

\section{vi. CFD modeling of spacer-filled membrane modules}

The use of Computational Fluid Dynamics (CFD) software has significantly aided the design of modules for membrane separations. CFD has been performed to analyze feed spacer performance [155-162], biofouling [163], mineral scaling [164] and particulate flow [165] in membrane modules. Development and verification of a particular model for momentum, species and energy conservation through comparison with experimental data are the critical first steps in the modeling of membrane systems. Subsequently, the verified model can be used to analyze different experimental conditions and module designs, drastically reducing the number of experiments needed to obtain an optimum design. 


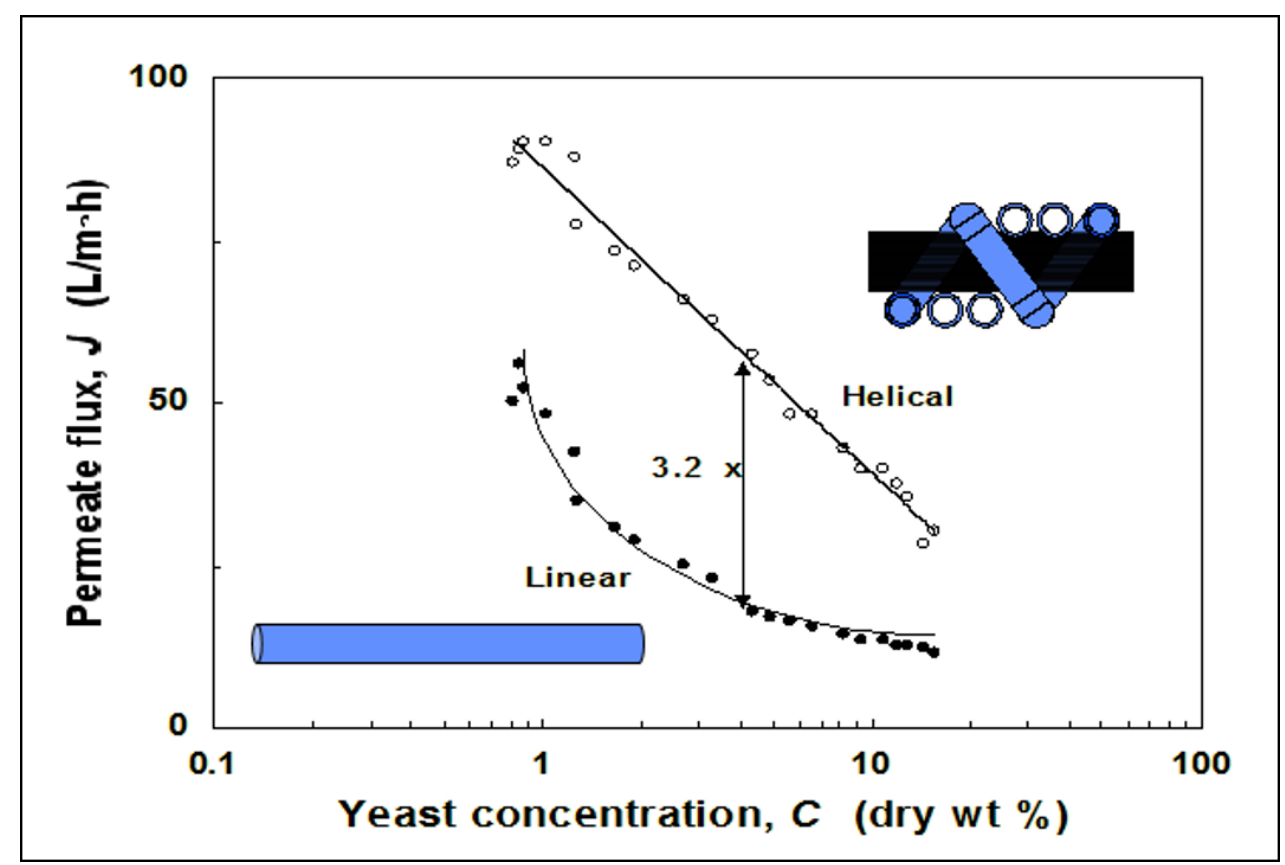

Fig. 6. Comparison of permeate flux while filtering yeast for a linear and a helical tube. Note that the linear tube is the same length as the coiled tube. Adapted from Luque et al., 1999 [154].

Fluid mechanics at membrane surfaces significantly influences the mass transfer characteristics of the separation process [166]. The mass transfer coefficient is a function of the Reynolds number of the fluid flow [167]. Spacers in membrane modules, which are primarily used to create channels for the feed flow by separating the membranes, also affect the flow pattern inside the module. Since spacers directly influence the fluid dynamics in the module, the mass transfer characteristics of the module are also affected. Introduction of spacers creates flow instabilities and turbulence, which reduce the effects of the mass transfer boundary layer at the membrane surface $[162,168]$. Flow instabilities enhance mass transfer by reducing the effect of concentration polarization [169]. 2D modeling is often inadequate to describe the mass transfer characteristics in spiral wound modules since the flow field is 3D in nature [169]. FimbresWeihs et al. modeled spacers with orientations of $45^{\circ}$ and $90^{\circ}$ relative to the direction of the incoming feed flow [169]. The $45^{\circ}$ spacer orientation exhibited increased mass transfer compared to the $90^{\circ}$ spacer orientation. It was found that form drag was the main factor resulting in pressure drop in the module. Certain types of form drag, however, were shown to be beneficial to the separation process through the formation of vortices [169]. The vortices promote flow separation and reattachment at the membrane surface, which greatly facilitates mass transfer since the fluid near the membrane surface is replenished more frequently [169]. In contrast, viscous drag facilitates mass transfer by forcing a reduction in the thickness of the mass concentration boundary layer [169]. The use of spacers increases the pressure drop in the module, and therefore the energy input required for the separation. The challenge is to create the optimum spacer design which increases the mass transfer through the membrane as much as possible while requiring only minimal increases in energy input. 
A major advantage of CFD is that the results may be much more accurate if the NavierStokes equations are solved directly without utilizing a model for turbulence [162]. Turbulence models are generally employed to obtain average values of the fluctuating components of the Navier-Stokes equations [162]. Santos et al. performed a CFD analysis of flow aligned spacers with an easily machined geometry for facile experimental comparison [162]. The cross section of the module studied was approximated as a rectangle since curvature was not expected to be practically significant due to the small height of the channel. Membrane permeation was not considered in the CFD modeling since the permeation velocity does not have a significant effect on the flow structure in the dense membranes used in RO. The no-slip boundary condition was used for both the channel and filament (i.e. spacer) surfaces. Twelve different spacer geometries were created by varying the distance between the centerline of the transverse spacers and by changing the number of longitudinal spacers. Fig. 7 shows close-up images of spacers used in RO modules in the desalination industry today.

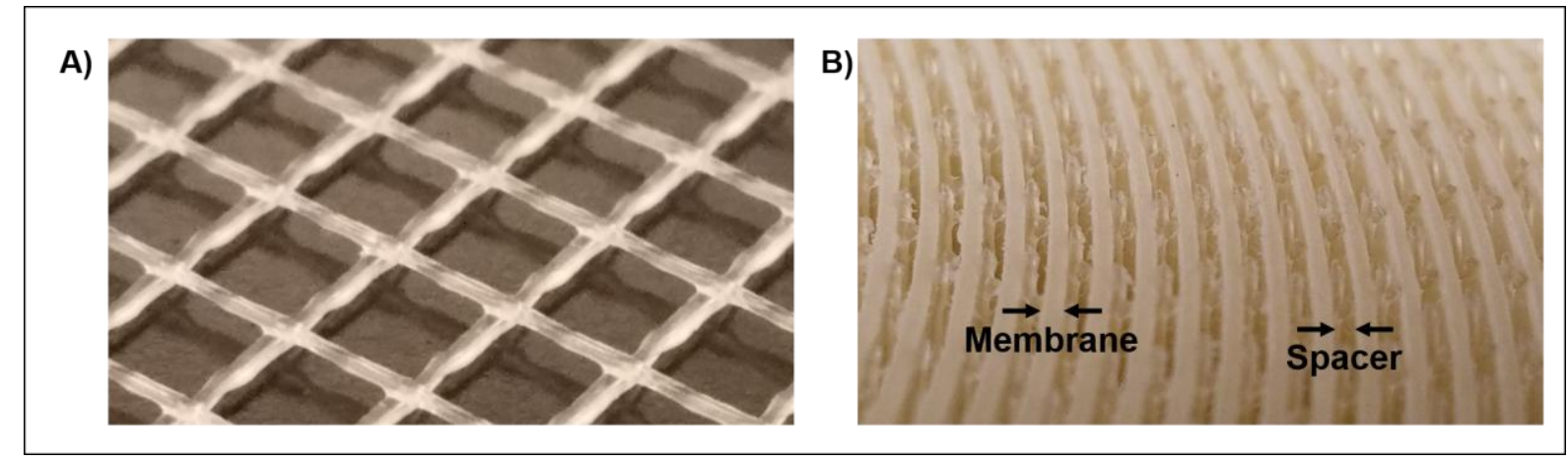

Fig. 7. Photographs of spacers used in the desalination industry. A) Close-up of membrane spacer and B) cross section of spiral wound membrane module with a spacer in between each membrane leaf (samples courtesy of Caleb Funk, Dow Water \& Process Solutions).

The mass transfer simulation results were only valid for the first geometrical unit that is repeated to construct the entire spacer structure, since at low Re a concentration boundary layer develops on the top surface. This boundary layer develops because the flow pattern is not disrupted along the top surface. The result is that subsequent repetitions of the geometrical unit are different than the first due to this growing boundary layer effect. The bottom surface, however, has its boundary layer periodically disrupted due to the flow over the transverse filaments, so the results for the bottom wall were expected to be representative of the entire module. A modified friction factor, $f$, was used to incorporate the spatial average of shear stress at the wall. The friction factor is defined as $\boldsymbol{f}=\left(\frac{\Delta P}{\boldsymbol{l}}\right)\left(\frac{\boldsymbol{h}}{\boldsymbol{\rho} \boldsymbol{U}_{0}^{2}}\right)$, where $\Delta \boldsymbol{P}$ is the pressure drop, $\boldsymbol{l}$ is the length of the channel, $\boldsymbol{h}$ is the channel height, $\boldsymbol{\rho}$ is the fluid density, and $\boldsymbol{U}_{\mathbf{0}}$ is the average channel fluid velocity. This expression differs from equation 1 through a factor of $-\left(\frac{h}{2 l}\right)$. The modified friction factor at the wall was defined as $\boldsymbol{f}_{\text {wall,i }}=\boldsymbol{\tau}_{\mathrm{wall}, \mathrm{i}}\left(\boldsymbol{h}^{2} \boldsymbol{\rho} / \boldsymbol{\mu}^{2}\right)$, where $\boldsymbol{\tau}_{\boldsymbol{w a l l , i}}$ is the shear stress evaluated at the wall. The power number, Pn, for crossflow in the module was defined as $\boldsymbol{P n}=\boldsymbol{f} \boldsymbol{R} \boldsymbol{e}^{\mathbf{3}}$. Two 
cases were studied: one with the channel height used as the characteristic dimension and the other which used the hydraulic diameter of the channel as the characteristic dimension, which takes the spacers into account.

Santos et al. used OpenFOAM CFD software to discretize the momentum and mass conservation equations [162]. To ensure simulation accuracy, a Courant number (Co) less than one was required, where the Courant number was defined as $\boldsymbol{C o}=\frac{\boldsymbol{U}_{\boldsymbol{o}} \boldsymbol{\delta} \boldsymbol{t}}{\boldsymbol{\delta} \boldsymbol{x}} . \boldsymbol{\delta} \boldsymbol{t}$ was defined as the time step and $\boldsymbol{\delta} \boldsymbol{x}$ was the mesh cell size in the direction of the fluid velocity. Simulations were performed with water at $25^{\circ} \mathrm{C}$ and a kinematic viscosity of $8.93 \times 10^{-7} \mathrm{~m}^{2} / \mathrm{s}$. Crossflow velocities studied in the module were 0.03-0.15 m/s, corresponding to Re from 67-336. A Schmidt number, which is the ratio of momentum diffusivity to mass diffusivity, of 600 was used (typical of a dilute $\mathrm{NaCl}$ solution). Simulation results showed that there are two regions in the friction factor vs. Re plots: one region at low Re due to laminar flow and another due to a transitional flow regime at higher Re. The friction factor decreases with increased transverse spacer distance and increases with increased number of longitudinal units. This is logical because head loss is expected to increase as more transverse filaments per unit length are encountered in the flow path.

Asymptotic relations in the form of $\boldsymbol{f}=\boldsymbol{a} \boldsymbol{R} \boldsymbol{e}^{\boldsymbol{b}}$ were fit to the data to determine parameters that fit the low Re and high Re cases. The values of $a$ and $b$ were different for each of the spacer geometries investigated and were determined through fitting the asymptotic relations to the data. The intersection of these asymptotes was used to define a critical value, $\boldsymbol{R} \boldsymbol{e}_{\boldsymbol{c}}$, for the onset of flow instability. As transverse filament distance decreased, the flow was stabilized and the critical Re number increased to higher values. For a given transverse spacer distance, increasing the number of longitudinal spacers did not change the critical Re number significantly. This was likely due to using the channel height as the characteristic dimension. When the channel hydraulic diameter was used instead, the dispersion of the critical Re numbers was reduced by $30 \%$, but did not yield constant critical Re number for all cases. The CFD model showed very good agreement with experimental results, indicating the model with periodic geometrical elements and cyclic boundary conditions hold. After the CFD model was verified, further CFD simulations were run. It was shown in the time-averaged velocity plot that circulation was induced at the corner of the upstream transverse filament for the spacer configuration with the largest distance between transverse filaments and without any longitudinal filaments. The circulation was due to boundary layer separation as the fluid could not maintain perfect contact with the filament. The size of this circulation zone increases with increasing $\operatorname{Re}$ until the critical Re is reached, when higher velocity fluctuations are observed by analyzing the magnitude of the Reynolds stresses. The velocity fluctuations are more significant in the bottom section of the channel between transverse filaments. Since filaments are not present in the top section, velocity fluctuations are damped out. It is evident from Fig. 8 that increasing the 
transverse spacer distance increases velocity fluctuations especially in the bottom section of the channel.

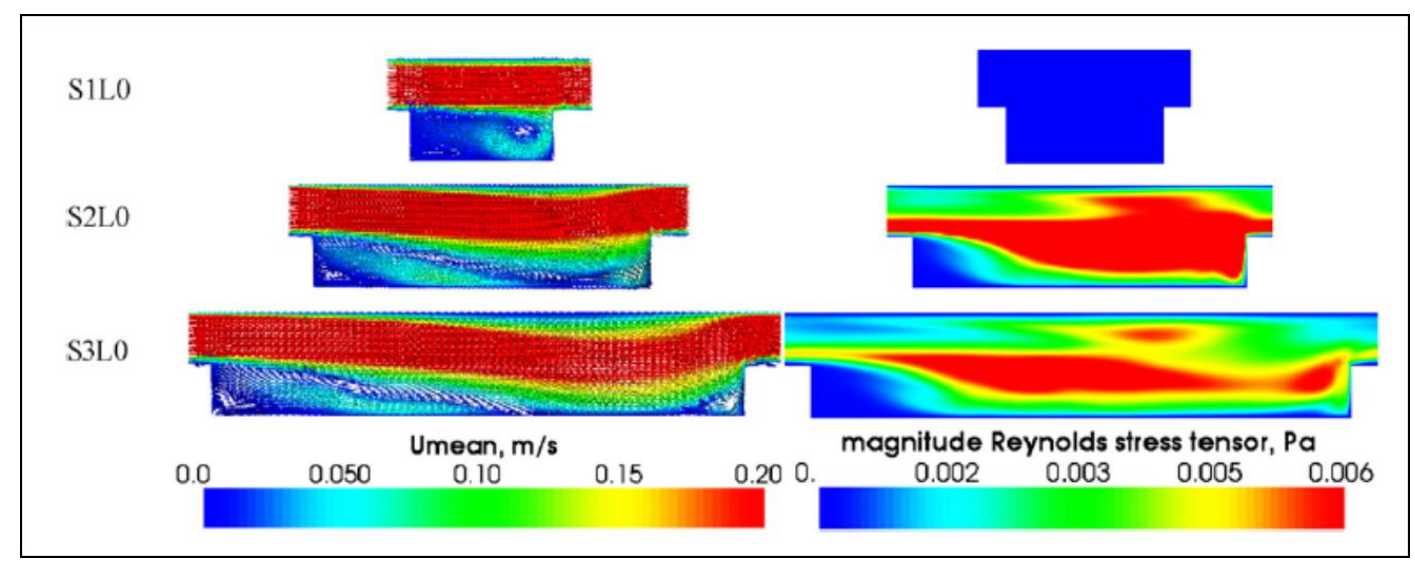

Fig. 8. CFD analysis of the S1LO, S2LO, and S3L0 spacers for $\mathrm{Re}=336$ : a) time-averaged velocity profile and b) magnitude of Reynolds stress tensor. Used with permission from Santos et al., 2007 [162].

The time average shear stress fluctuations are higher on the bottom wall. This is due to vortex shedding and transient flow. The number of longitudinal filaments does not seem to influence the flow profile or transition from laminar to transitional flow for a particular intertransverse filament distance. A linear relation was observed between the modified friction factor (which was defined above) and the mean Sherwood number in the channel. The Sherwood number used here is defined as $\boldsymbol{S h}=\frac{\boldsymbol{k}_{\boldsymbol{c}} \boldsymbol{h}}{\boldsymbol{D}_{\boldsymbol{A B}}}$, where $\boldsymbol{k}_{\boldsymbol{c}}$ is the local mass transfer coefficient and $\boldsymbol{D}_{\boldsymbol{A} \boldsymbol{B}}$ is the mass diffusion coefficient. Depending on the location of the membrane, the optimal geometry for enhanced mass transfer will be different. This allows the modified friction factor to be used to predict the optimum mass transfer efficiency. Using only the modified friction factor would result in less experimental/computational work to determine the ideal spacer geometry for the application.

Subramani et al. performed CFD simulations of open channel flow and compared the results with flow around cavity, submerged and zigzag type filaments [170]. A cross-section view of simulation results for these three different spacer designs are shown in Fig. 9.. The cross-section is taken in a vertical plane parallel to the flow to show the effect of the spacers on the flow pattern. The membrane is located on the top surface in Fig. 9, orthogonal to the plane of the paper. The cavity geometry includes spacers that lie at the bottom surface of the channel. The submerged geometry contains spacers that are completely immersed in the flow and do not touch the channel top or bottom. The zig zag geometry employs spacers which alternate from being attached to the top and bottom surfaces, causing the fluid to flow in a zigzag type pattern. Under the conditions studied, the zigzag configuration had larger stagnant zones (Fig. 9(C)) due to the changing direction of fluid flow that increased concentration polarization, making it the least effective spacer orientation. The other geometries have faster moving fluid near the 
membrane surface, reducing the boundary layer thickness. Similar to the work performed by Santos et al. discussed previously, there will be a trade-off between the increased mass transfer due to the addition of spacers and increased energy cost due to the higher pressure drop. Therefore, careful optimization must be performed to determine the most efficient operating point.

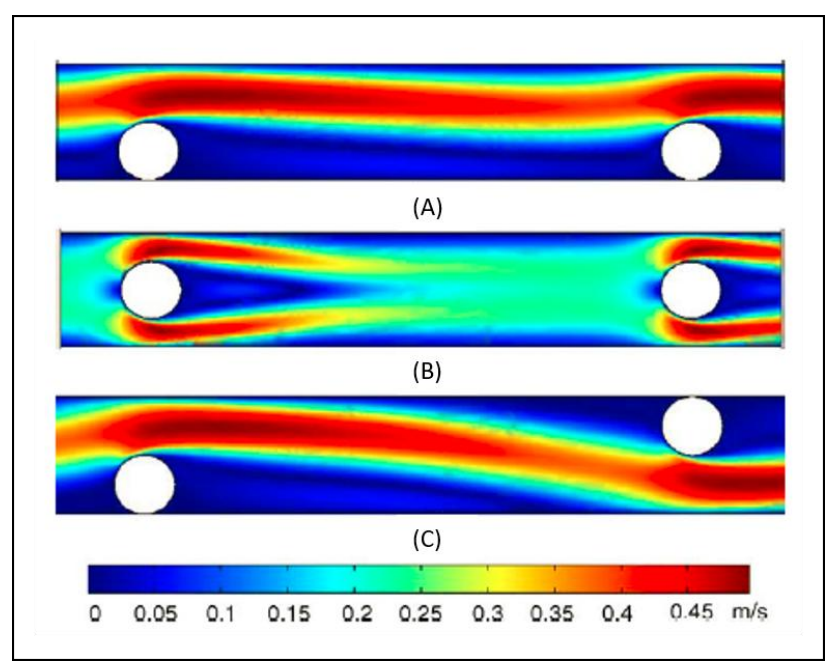

Fig. 9. Side-view illustrations of fluid flow through short sections of spacer-filled channels with: (A) cavity, (B) submerged, and (C) zigzag spacer configurations. Flow is from left to right, as shown by the arrows, and the membrane is located above the spacers and orthogonal to the plane of the paper. Used with permission from Subramani et al., 2006 [170].

It has been shown that CFD is a useful tool to predict optimum spacer geometry and design, as well as effects of fouling on the flow patterns in a module. Using CFD can drastically reduce the number of experiments needed to find an optimum spacer design to increase mass transfer while keeping power requirements at a minimum.

\section{vii. Particle deposition}

Lyster et al. monitored the scaling of an RO membrane surface with gypsum in an optically transparent plate-and-frame RO cell and compared the results with a 3D hydrodynamics and mass transfer model [164]. The gypsum scaling was found to be non-uniform on the membrane surface, with increased scaling observed as the fluid moves from the entrance to the exit of the RO cell. Near the concentrate exit from the module, the highest scaling was observed due to large recirculation zones which reduce mass transfer from the membrane surface. To describe particulate flow in curved ducts, Prashant et al used multi field CFD [165]. 


\section{Fouling Analytics of Pre-treatment}

\section{i. 3D Modeling}

Experimentally, Belfort and Guter (1972) were the first to measure the effect of plastic spacer design on fluid flow and mass transfer to a membrane surface using developer and photographic film [168]. Vrouwenvelder et al. used CFD to model the biofouling of RO membranes with and without spacers [163]. Two types of pressure drop are important in membrane processes: transmembrane pressure drop (i.e. pressure difference between feed and permeate) and feed spacer channel pressure (FCP) drop (i.e. pressure difference between feed and concentrate lines). Both pressure drops vary with axial distance along the membrane.

As time increases, channeling develops on the surface of the spacer, resulting in regions with poor flow and regions with higher flow. This qualitatively confirms the model as it predicts the fouling behavior with time. Fig. 10 compares the flow patterns near the membrane surface with and without feed spacers. Feed spacer fouling has a much stronger impact on the velocity profile than membrane fouling only. Therefore, models that describe fouling should also include fouling of the spacer geometry as well as that of the membrane surface. Biofouling in RO modules is an FCP drop dominated problem, even when the feed to the module is pre-treated.

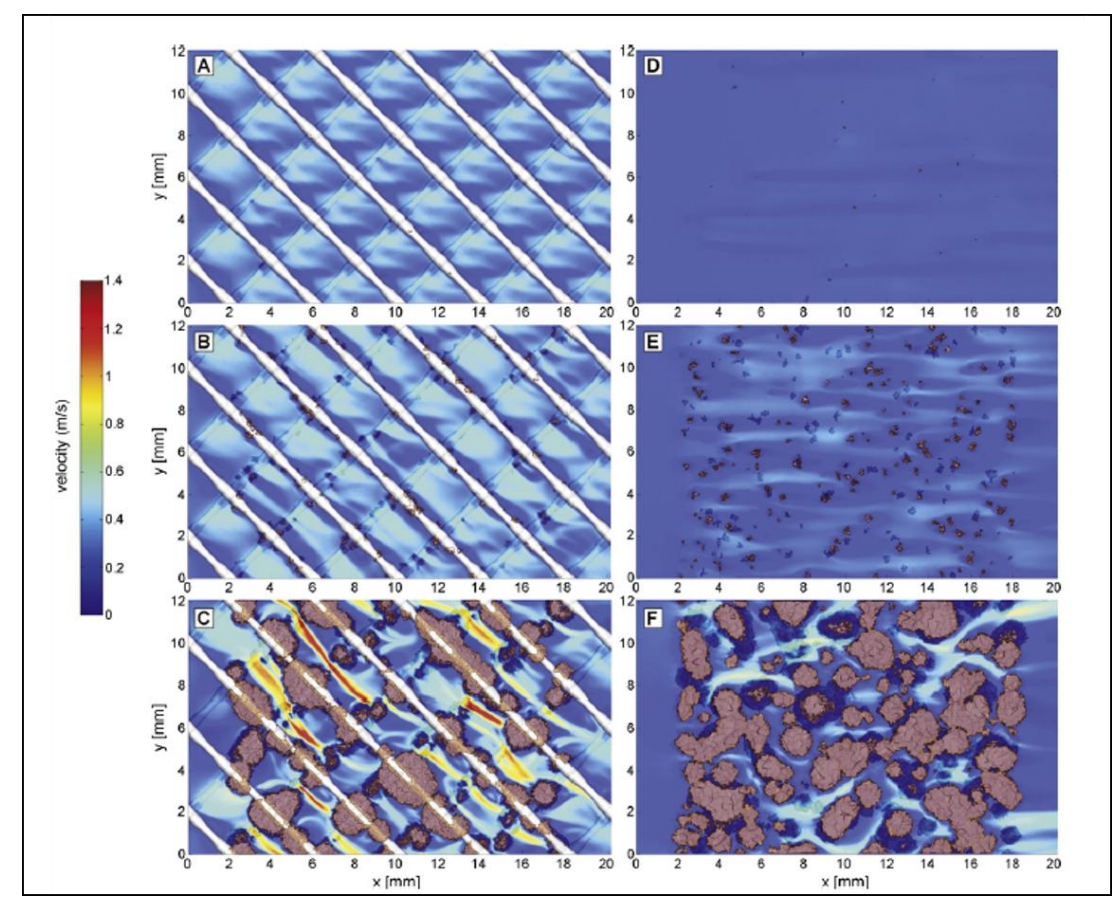

Fig. 10. Calculated flow velocity field at different times with (A-C) and without (D-F) feed spacer, presented in sections at $\mathrm{z}=585 \mathrm{um}$ (75\% of the feed channel height). The times are: (A and D) 6h, (B and E) 42h, and (C and F) 80h. Used with permission from Vrouwenvelder, et al., 2010 [163]. 


\section{ii. Quantitative analysis and membrane performance comparison}

Since desalination plants have used ultrafiltration as a pretreatment method, it is important to predict and understand their fouling performance. Most previous work that focused on understanding membrane fouling involved experiments. Particle trajectory analysis is an exception to this rule [165, 171-177]. Another exception is the global model and algorithm that predicts the performance of crossflow during MF and UF in the laminar flow regime [178]. A typical algorithm is shown in Fig. 11 that simulates and optimizes an ultrafiltration process. The model accounts for solute polydispersity, ionic environment, electrostatics, membrane properties and operating conditions. Computer programs were written for different versions of the model algorithm that can optimize MF/UF processes rapidly in terms of yield, purity, selectivity, or processing time.

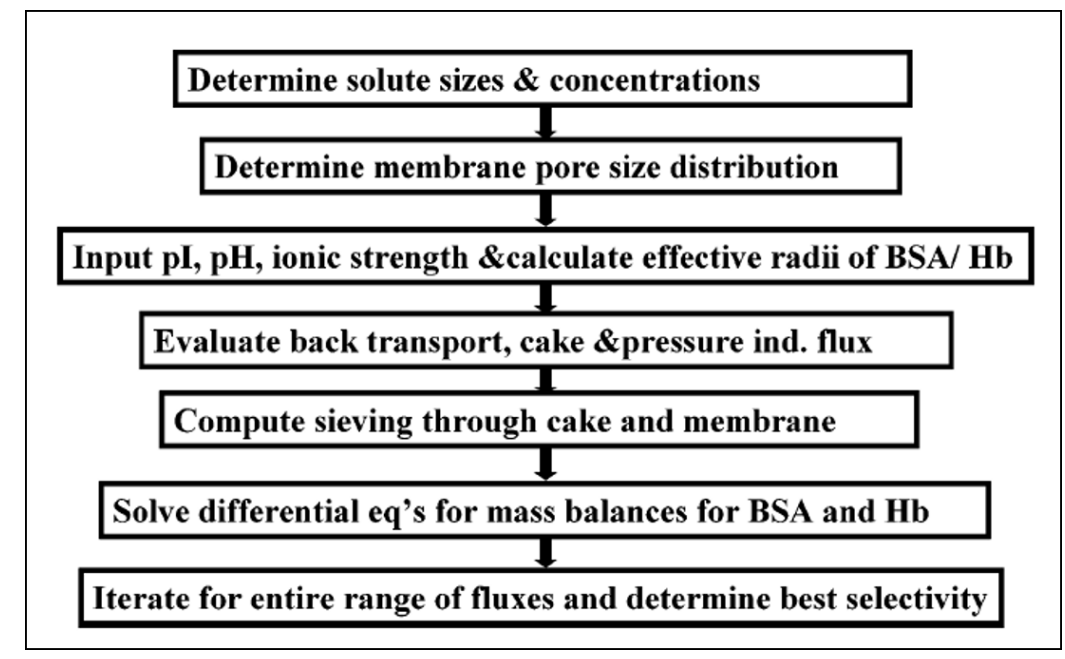

Fig. 11. Flow sheet of the algorithm used in the global MF/UF model to determine the maximum selectivity between hemoglobin and bovine serum albumin in a batch ultrafiltration mode. Figure used with permission from Baruah et al., Biotechnol. Prog. 2005, 21, 1013-1025 [178].

This model and algorithm is an invaluable technique to rapidly design new or optimize existing MF and UF processes separately or in combination in both pressure-dependent and pressure-independent regimes. Its predictive capabilities for variations in solution conditions ( $\mathrm{pH}$ and ionic strength), membrane properties (mean pore size and permeation flux) and fluid mechanical conditions (shear rate) are demonstrated with details of the model by Baruah et al. (2005) [178].

\section{iii. Fouling models and adaptation to crossflow}

Fouling models: Membrane fouling phenomena may involve pore (or surface) blockage, pore constriction, and cake formation, shown schematically in Fig. 12. These so-called "classical" fouling mechanisms act to reduce the accessible number of pores, reduce the effective pore cross sectional area, or introduce a resistance in addition to the membrane resistance, 
respectively. As implied in the figure, the mechanisms that occur depend on the membrane pore size distribution relative to the size distribution of feed components, and multiple mechanisms may occur. One approach to model fouling is to incorporate resistances, in addition to the membrane resistance, into the flux equation.

$$
J_{v}=\frac{\Delta P-\sigma_{o} \Delta \pi}{\mu\left(R_{m}+\sum R_{i}\right)}
$$

The result is the resistance-in-series model, where $R_{i}$ represents additional resistances caused by fouling; this approach is typically used to incorporate the additional resistance, $R_{\mathrm{c}}$, due to cake formation. The assumptions inherent in different fouling models will be briefly reviewed; mechanisms and flux equations are summarized in Table 1.

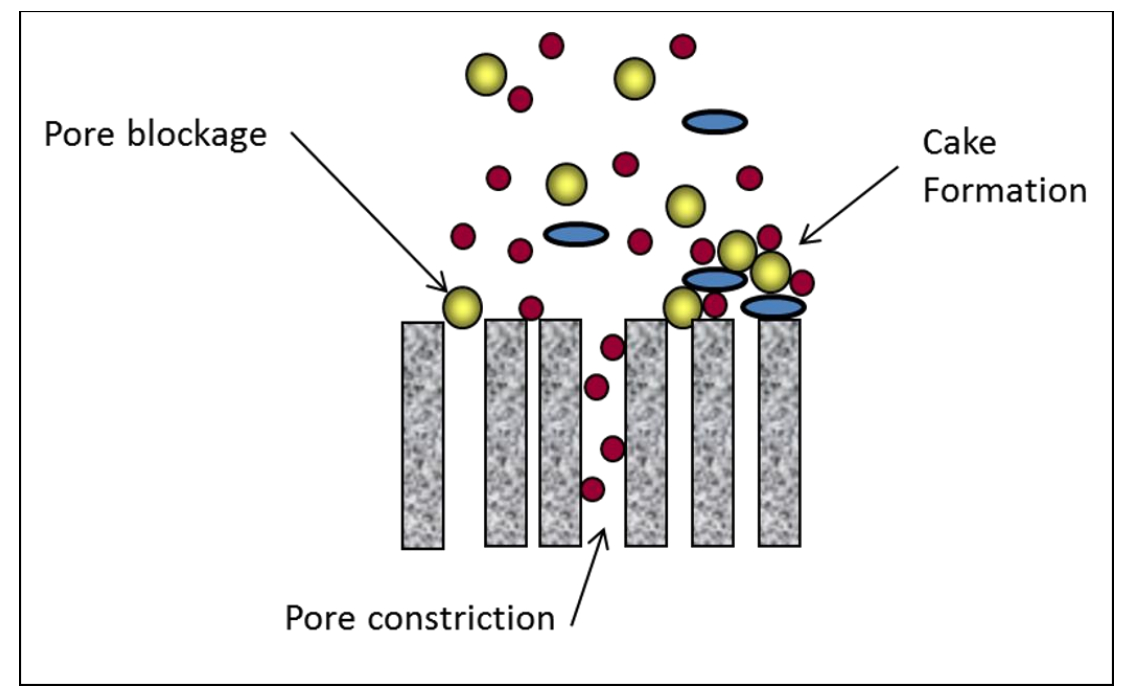

Fig. 12. Schematic depictions of the classical fouling mechanisms. Note the distribution of feed component sizes and membrane pore sizes.

During cake formation, it is assumed that the time rate of change in flux is proportional to the change in cake layer resistance, $R_{c}$, expressed as the product of specific resistance, $\alpha_{\mathrm{c}},\left[\mathrm{m}^{-1}\right.$ $\left.\mathrm{kg}^{-1}\right]$ and cake mass, $m_{c}$. The buildup of cake mass is then assumed to be proportional to the rate of advective transport to the membrane surface, $J_{v} C_{b}$.

The effects of pore blockage and pore constriction on membrane properties are introduced by first expressing membrane resistance in terms of the Hagen-Poiseuille equation for laminar flow. When pore blockage is the operative fouling mechanism, prior to the establishment of a cake layer, the time rate of change in flux is proportional to the rate of change in the number of accessible pores (or pore area, $A_{p, T}$ ). The change in pore area is assumed to be proportional to the advective transport of solute to the membrane surface. The complete pore blockage parameter, $\alpha_{\mathrm{cb}}$, is equal to the area of pores blocked per unit mass of solute transferred to the surface $\left[\mathrm{m}^{2} \mathrm{~kg}^{-1}\right]$. 
The intermediate pore blockage model is similar to the complete pore blockage model, but allows particles to deposit onto previously deposited particles. There is an equal probability for particles to deposit on previously deposited particles (in which case they do not reduce flux further) or on the unfouled membrane surface, where they completely block pores and contribute to further flux decline. Therefore, the rate of pore blockage is assumed to be proportional to the ratio of the unblocked area to the total area. Xu and Chellam [179] found that initial flux decline due to deposition of rod-shaped bacteria (Brevundimonas diminuta and Serratia marcescens), prior to the secretion of new extracellular polymeric substances, was quantitatively described the intermediate blocking law before transitioning to cake filtration at later times. Empirical deposition factors were introduced to account for the morphology of bacterial deposits.

When pore constriction (aka standard blocking) is the operative fouling mechanism, the time rate of change in flux is proportional to the rate of change in the pore radius. The change in pore volume is assumed to be proportional to the rate of advective transport of solute to the membrane surface. The pore constriction parameter, $\alpha_{p c}$, is equal to the volume of pores blocked per unit mass of solute transferred to the surface $\left[\mathrm{m}^{3} \mathrm{~kg}^{-1}\right]$. Table 1 summarizes classical fouling mechanisms and models.

Table 1. Classical Fouling Mechanisms and Models

\begin{tabular}{|l|l|l|l|}
\hline $\begin{array}{l}\text { Constant } \\
\text { Pressure }\end{array}$ & Mechanism & Flux Equation & Rate Constant \\
\hline $\begin{array}{l}\text { Cake } \\
\text { Formation }\end{array}$ & $\frac{d R_{c}}{d t}=\alpha_{c} J_{v} A_{m} C_{b}$ & $J_{v}=J_{v, o}\left[1+k_{c} t\right]^{-1 / 2}$ & $k_{c}=\frac{2 \alpha_{c} A_{m} C_{b} J_{v, o}}{R_{m}}$ \\
\hline Pore blockage & $\frac{d A_{p o r e, T}}{d t}=-\alpha_{b} J_{v} A_{m} C_{b}$ & $J_{v}=J_{v, o} \exp \left[-k_{b} t\right]$ & $k_{b}=\frac{J_{v, o}}{N_{o}} \frac{\alpha_{b} C_{b}}{\pi r_{p}^{2}}$ \\
\hline $\begin{array}{l}\text { Intermediate } \\
\text { blocking }\end{array}$ & $\frac{d A_{p o r e, T}}{d t}=-\alpha_{\mathrm{int}} J_{v} A_{m} C_{b} \frac{A_{p o r e, T}}{A_{p o r e, o}}$ & $J_{v}=\left[\frac{1}{J_{v, o}}-k_{\mathrm{int}} t\right]^{-1}$ & $k_{\mathrm{int}}=\frac{\alpha_{\mathrm{int}} C_{b}}{\pi N_{o} r_{p}^{2}}$ \\
\hline $\begin{array}{l}\text { Pore } \\
\text { constriction }\end{array}$ & $\frac{d}{d t}\left(\pi r_{p}^{2} \delta_{m}\right)=-\alpha_{p c} J_{v} A_{m} C_{b}$ & $J_{v}=J_{v, o}\left[1+k_{p c} t\right]^{-2}$ & $k_{p c}=\frac{J_{v, o} \alpha_{p c} A_{m} C_{b}}{\pi \delta_{m} r_{o}^{2}}$ \\
\hline
\end{tabular}

Features of the flux versus time plots vary subtly for different mechanisms, making it difficult to distinguish among them from such plots. A better approach is to use the relationship between flux and volume filtered, $J_{v} A d t=d V$, to develop analogous analytical relationships between flux and filtration volume, and filtration volume versus time. Linear forms of these models can be used to graphically assess the fouling mechanism. Such "characteristic coordinates" include $J_{v}$ versus $V$ for the complete blockage model, $t / V$ versus $t$ for the pore 
constriction model, and $t / V$ versus $V$ for the cake formation model. Differences in fouling mechanisms can become clearer when the data is plotted on coordinates that linearize the data for one of the models. For example, when data is plotted on $t / V$ versus $t$ coordinates, the pore constriction model plots as a straight line whereas the complete blockage model is concave upward and the cake formation model is concave downward, clearly illustrating different behavior for the three models.

For dead-end filtration under constant applied pressure, the differential rate laws corresponding to pore blockage, pore constriction, and cake formation can all be formulated as a single equation as proposed by Hermia [180]:

$$
\frac{d J_{v}}{d t}=k J_{v}\left(J_{v}\right)^{2-n} \text { or } \frac{d^{2} t}{d V^{2}}=k\left(\frac{d t}{d V}\right)^{n}
$$

where $k$ is a rate constant or "fouling coefficient", with units that depend on the value of $n, n$ is a dimensionless filtration constant, and $V$ is the total volume (or mass) filtered $\left[\mathrm{m}^{3}\right]$. The term $d t / d V$ is equal to $1 / J A_{m}$, which is the differential time needed to collect a unit volume of permeate, i.e., $\mu R_{T} / \Delta P A_{m}$. The fouling mode is reflected in the value of the filtration constant: i) cake formation corresponds to $n=0$; ii) pore constriction (standard blocking) corresponds to $n=$ 1.5; and, iii) complete pore blocking corresponds to $n=2$. Taniguchi et al. [181] used this approach to determine the causes of fouling during UF treatment lake water containing humic substances (natural organic matter), and found that pore blockage was the cause of flux decline during the initial period of filtration, but over time cake formation became most important.

Membrane comparison: In many membrane research and engineering applications it is necessary to compare the performance of different membranes, to identify the best selection to meet process goals, which usually include optimizing permeability, rejection characteristics, and flux decline due to fouling. A widely employed approach is to compare flux versus time curves for different membranes; experiments are often designed such that the initial flux is the same for all experiments, to assure that the convective transport of foulants to the membrane is similar. Membranes having smaller flux decline are generally considered as having lower fouling potential and hence higher performance. However, as we will show, flux decline curves often depend on membrane hydraulic permeability, which is often not accounted for in many of the fouling studies that appear in the literature.

Comparisons based on flux decline can be misleading when membranes having different inherent (initial) permeability are evaluated. Consider the resistances in series model, Eq, 7, incorporating membrane resistance and a fouling resistance $R_{F}$ that depends on time (or volume throughput); the sum of membrane and fouling resistance is the total resistance, $R_{T}$. As discussed above, and as idealized by the Hagen-Poiseuille equation, the membrane resistance is related to membrane properties such as thickness, pore density, and pore radius. The time rate of change in flux due to fouling exhibits an inverse dependence in the membrane resistance: 


$$
\frac{d J_{v}}{d t}=-\frac{\Delta P}{\mu} \frac{1}{\left(R_{m}+R_{F}\right)^{2}} \frac{d R_{F}}{d t}
$$

In addition, the time rate of change in fouling resistance, $d R_{F} / d t$, also may depend on membrane properties. Therefore, the rate of flux decline is smaller for membranes having greater resistance, other factors, such as membrane-foulant interactions, being equal. Ideally, we wish to compare the fouling potential of different membranes independent of membrane resistance (or permeability). Classical fouling models can be employed to identify whether this is possible, and which approaches are best. In this analysis, we assume two different membranes have the same pore size and porosity, but different thickness, and hence different resistance. We assume the membranes have the same surface chemistry, and hence the same affinity for foulants in the feed, as reflected in the same fouling rate constants $\left(\alpha_{c}, \alpha_{c b}, \alpha_{i b}\right.$, or $\alpha_{p c}$, values). They are operated at the same initial flux (hence different transmembrane pressure values) and the feed concentration is also the same.

When pore blockage is the operative mechanism, two membranes having different resistances can be compared on either flux vs time or volume throughput vs time coordinates. That is, as long as the fouling rate constant is the same, the same curve is found, regardless of the membrane resistance. Therefore, differences in the flux vs time curve will be due to differences in fouling potential, not membrane properties.

When cake formation is the operative mechanism, two membranes having different resistances cannot be compared on either flux vs time or volume throughput vs time coordinates. That is, even though the fouling rate constant is the same, the rate of flux decline is lower for the membrane having the higher resistance; therefore, differences in the flux vs time curve will be due to differences in membrane properties, not fouling potential. However, because fouling resistance depends only on cake formation, not membrane properties, it is possible to evaluate fouling potential independent of membrane resistance by plotting fouling resistance, $R_{F}$, vs volume throughput; this is illustrated in Fig. 13. When pore constriction (standard blocking) is the operative mechanism, the fouling potential of two membranes having different resistances cannot be compared independently from the resistance. As with cake formation above, even though the fouling rate constant is the same, the rate of flux decline is lower for the membrane having the higher resistance; therefore, differences in the flux vs time curve will be due to differences in membrane properties, not fouling potential. Unfortunately, there is no set of coordinates that can be used to isolate the fouling potential of the different membranes independent of resistance. To overcome this limitation, and to provide a more general basis for comparing membrane performance regardless of the fouling mechanism, we recommend employing an energy criterion:

$$
\text { Energy }=\int J_{v}(t) A_{m} \Delta P d t=V(t) \Delta P
$$




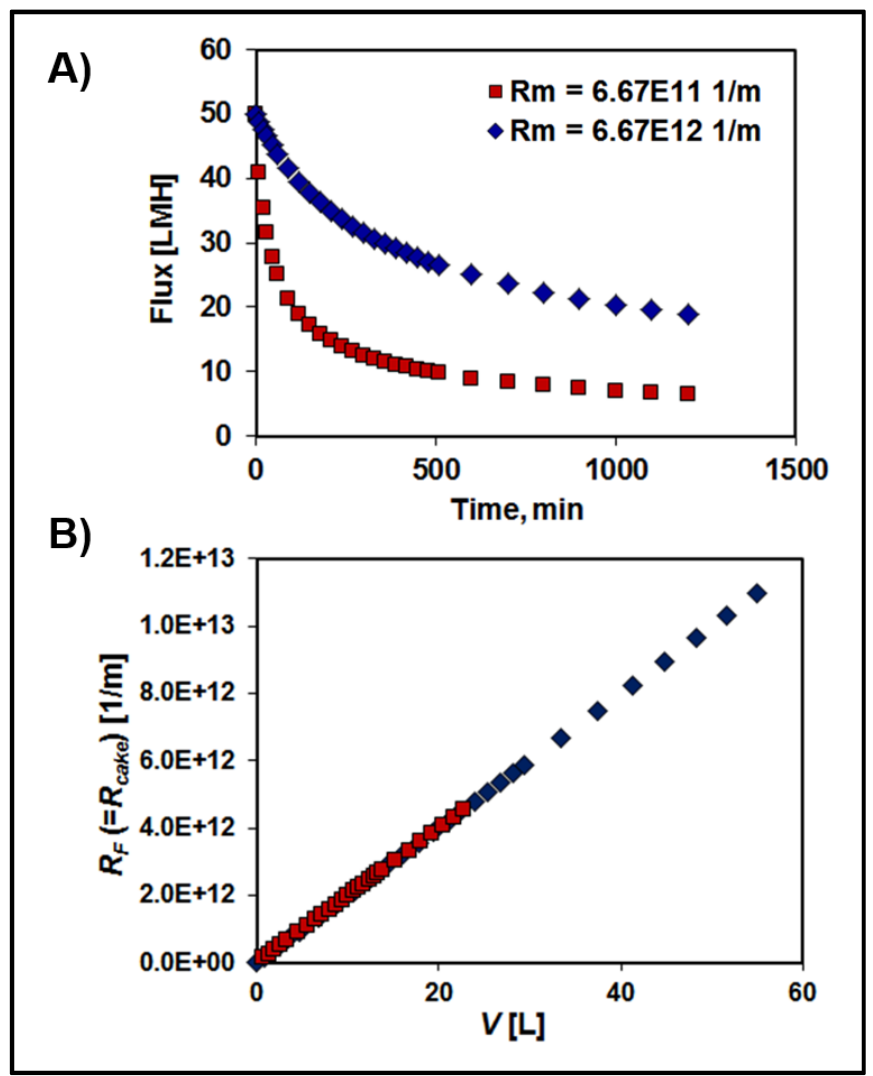

Fig. 13. Two membranes having the same fouling potential (cake specific resistance) but different resistance values cannot be compared on flux vs time coordinates; the membrane having the higher resistance appears superior, but only because it has a higher resistance (Plate A). Fouling potential can be examined independent from membrane resistance by plotting fouling resistance vs. volume throughput (Plate B).

The advantage of the energy criterion is that it accounts for the effects of both flux decline, and initial resistance. Membranes having high initial resistance require greater transmembrane pressure drop to yield the same starting flux as a low resistance membrane, thus negating and apparent benefit of a slower rate of flux decline when process cost (energy consumption) is considered. This is illustrated in Fig. 14, where fouling is by the pore constriction mechanism, and the two membranes compared have the same fouling rate constant.Although the membrane having the higher resistance exhibits slower flux decline, it is apparent that the performance of the membrane is not superior when energy consumption is taken into account.

Effects of crossflow: Crossflow can enhance mass transfer processes that induce back transport from the membrane surface, reducing the net flux of foulant to the membrane surface. Such back transport can result from diffusion, inertial lift and shear forces. In terms of classical fouling models shown in Table 1, the net advective transport of solute to the membrane surface is now proportional to $J_{\mathrm{v}}-J^{*}$, where $J^{*}$ can be thought of as an effective velocity associated with mass transfer away from the membrane surface [182] or a critical flux [183, 184]. 


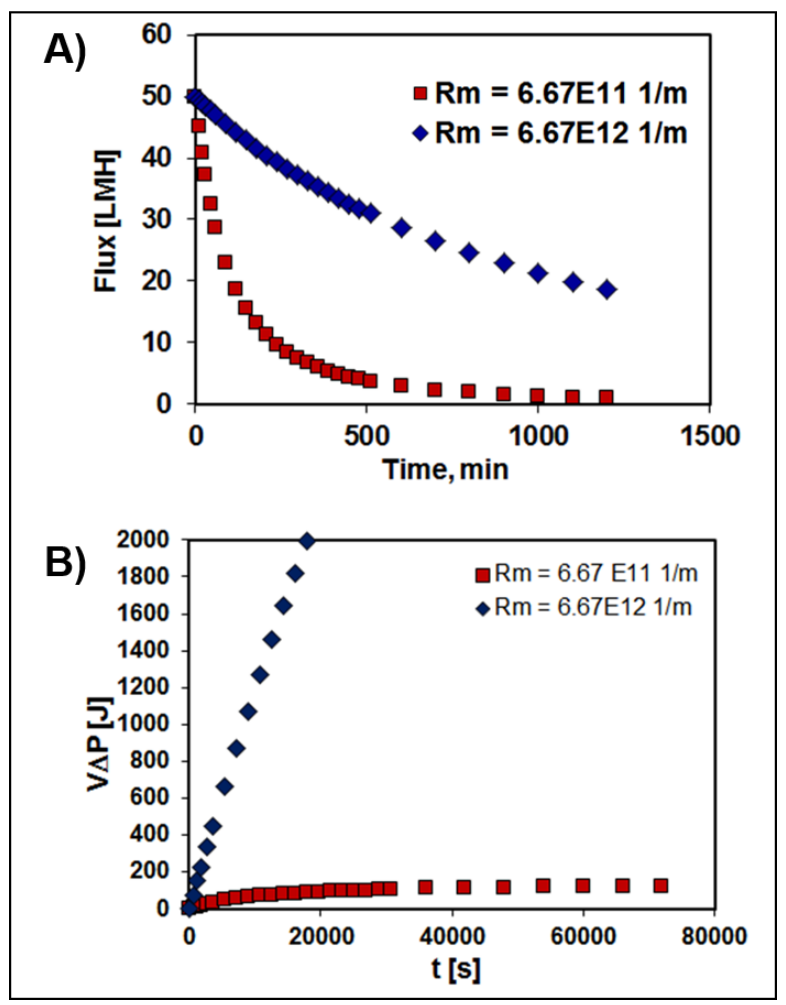

Fig. 14. Two membranes having the same fouling potential (pore constriction) but different resistance values cannot be compared on flux vs time coordinates; the membrane having the higher resistance appears superior, but only because it has a higher resistance (Plate A). Membrane performance can best be assessed by considering energy consumption (Plate B) which shows that when fouling potential is the same, the lower resistance membrane is superior, even though it exhibits greater flux decline.

\section{iv. Models using 3 mechanisms}

Combined mechanisms: Ho and Zydney [185] developed a model that combines pore blockage and cake filtration modes of fouling, and later Duclos-Orsello and Ho [186] developed a model that incorporates all three classical fouling mechanisms. Bolton et al. [187] also present models based on different combinations of classical fouling models. In both the pore blockage and cake filtration model, and the three mechanism model, which also incorporates pore constriction, total flow through the membrane, $Q_{T}\left[\mathrm{~m}^{3} \mathrm{~s}^{-1}\right]$, is the sum of flow through unblocked pores and through "blocked" pores:

$$
Q_{T}=J_{v} A_{T}=Q_{\text {unblocked }}+Q_{\text {blocked }}=J_{\text {unblocked }} A_{\text {unblocked }}+J_{\text {blocked }}\left(A_{T}-A_{\text {unblocked }}\right)
$$

where $A_{T}=A_{\text {unblocked }}+A_{\text {blocked }}$. Consistent with the pore blockage model, the rate of pore coverage (the rate of loss of open area) is assumed to be proportional to the advective transport of solute, leading to an exponential decrease in open are with time. In the three-mechanism model, flux through unblocked pores is given by the pore constriction model. Flow through the blocked region is assumed to be described by the resistance in series model discussed above. 
When only pore blockage and cake formation are considered, resistance due to pore constriction is neglected, whereas it is included in the three-mechanism model.

In the three mechanism model, initially pore constriction occurs through all the open pores while the membrane surface is blocked gradually by deposited solute to form an inhomogeneous blocked area. Once a pore is blocked by an aggregate deposited on the surface, no further pore constriction can occur, but as in the two-mechanism model, a cake layer subsequently will build up over the blocked area. These models have been used to successfully describe protein filtration [185], filtration of natural colloids [181] and have been shown to converge towards the correct single mechanism when experimental conditions were designed to make that mechanism dominate the fouling process [186].

The above discussion of fouling models has focused on constant pressure operation, i.e., $\Delta P$ was treated as a constant, and flux declined with time as fouling occurred. In many largescale applications, constant flux operation is preferred, especially in the biotechnology industry. All of the above fouling relationships have analogies for constant flux operation [188-190]. In addition, the solute deposits in the above discussion were treated as incompressible. Xu and Chellam [190] confirmed that colloidal silica formed incompressible cakes whereas bacteria and natural colloids formed cakes that were compressible. Bacteria compressed in a straight-line manner whereas power-law compressibility was observed for coagulated natural colloids during constant pressure MF. The resistance of colloidal cakes was dominated by morphology, not the mode of deposition, confirming that the cake permeability was determined by the instantaneous pressure.

\section{v. Biofouling models}

Chellam and Cogan $[189,191]$ have presented a resistance in series model to account for fouling (flux decline in constant pressure or pressure increase during constant flux filtration) that results from bacterial deposition and subsequent EPS production. Resistances include contributions from the membrane, $R_{m}$, bacteria, $R_{a}$, and EPS, $R_{e}$. Resistance from deposited bacteria is assumed to follow a saturation model

$$
\boldsymbol{R}_{a}=\frac{\mu_{a} \boldsymbol{B}}{\boldsymbol{K}+\boldsymbol{B}}
$$

Where $B$ is the bacterial population and $\mu_{a}$ and $K$ are rate parameters. The rate of deposition depends on the open membrane area $A_{\text {open }}$, which declines exponentially. A unique feature of this model is the incorporation of EPS production; resistance due to EPS is proportional to the EPS concentration, $(\mathrm{E}), R_{e}=\kappa_{1} E$. The production of EPS is assumed to be controlled by a quorum sensing "switch", whereby production is low until bacteria reach a threshold density, $B^{*}$, after which it increases rapidly. This phenomenological behavior is captured qualitatively by a production law, $G$ : 


$$
\frac{d E}{d t}=\kappa_{1} G(B, E) \text { where } G=\frac{\kappa_{1}\left[1+\tanh \left(\gamma\left(B-B^{*}\right)\right)\right]}{2(1+E)}
$$

This unified model was applied to single-species bacterial cultures in constant flux, dead-end microfiltration. The model was able to predict experimental pressure data well, using parameters calibrated previously in constant pressure filtration. This finding also confirms that hydraulic resistance is determined by instantaneous pressure, not operating mode. The authors also fit experimental data with conventional blocking law models. Both traditional blocking law models, which employed a linear compressible cake blocking law, and the unified model provided good fits to the data, except at low fluxes, where the blocking law models provided better fits. The authors proposed that a limitation of the unified model may be in how bacterial deposition and changes in open area are modeled. Still, the model showed promise of predicting filtration dynamics with few a priori adjustments once parameters are determined from the type of bacteria, membrane, and operating parameters.

Laspidou et al. [192] advocate modeling as a platform to integrate experimental observations of biofilms and physical, chemical and biological processes (e.g., community structure) occurring at different spatial and temporal scales. Models of increased complexity are developed to accommodate multiple biomass species and multiple biomass types (active biomass, inert biomass and extracellular polymeric substances (EPS); the physical structure of a biofilm in two or three dimensions; and how biomass density varies throughout the biofilm. Biofilm structure is important because there is a feedback between the effect of the biofilm on the surrounding fluid, and the effects of the fluid (forces that act on the biofilm and cause detachment) on the biofilm. Advances in microscopy have revealed that biofilms do not grow in flat layers, but have channels and pores, and mushroom like protrusions into the fluid, depending on conditions [193].

The way a model captures such features depends on how biofilm growth proceeds, i.e., the rules - the system of logic and assumptions - that govern how biomass is distributed. Two approaches have received the greatest attention; Laspidou et al. [192] review the advantages of using cellular-automata (CA) and individual-based (IbM) models to simulate biofilm growth on RO membranes.

Cellular automata models employ an array of compartments that are allowed to populate with bacterial cells to a predetermined capacity. In the Unified Multi-Component Cellular Automaton (UMCCA) model by Laspidou and Rittmann, biomass grows at a rate defined by the substrate concentration and the microbial kinetic rate parameters for substrate uptake, metabolism, maintenance, and death. When a compartment reaches capacity, the biomass is subdivided to simulate cell division. The new growth causes biomass to be "pushed" along the shortest path to a nearby unoccupied cell chosen randomly from among all equidistant nearestneighbors. Active biomass produces inert biomass and EPS, but these components do not move; 
this is consistent with the role of EPS as a structural component of biofilms, and with inert biomass acting as a byproduct of active growth.

In individual-based models, the microbial processes discussed in cellular automata models are treated at the individual cell level, and not with a predefined grid. Tracking individual cells is more computationally intensive than cellular automata models. Growth patterns (e.g. exponential growth) emerge only as a result of the substrate uptake, metabolism and maintenance of individual cells. One approach is to represent the biofilm structure by a collection of non-overlapping hard biomass spheres, which could represent single bacteria or a micro-colonies. When spheres reach a defined density, they divide and disperse in random directions; biomass spreading then occurs by minimizing the overlap of spheres.

The need to define a lattice in celluar automata models presents limitations, because biomass can only move in a finite number directions defined by how the lattice is arranged, and different lattice systems can influence the resulting biofilm structure even for the same propagation rules. As a result of the stochastic rules for biomass redistribution, a high degree of internal mixing of multiple species may occur within a colony. However, as biomass decays, compartments can empty leaving on the EPS structure, and thus simulating changes in porosity observed experimentally in aged biofilms. Also, it is possible to incorporate biofilm consolidation into cellular automata models, allowing biofilm density to change over time.

Individual based models idealization of biomass as hard spheres is unrealistic, but these models offer greater flexibility because there is no lattice to constrain the movement of biomass. Model parameters define the spacing among biomass particles, biomass packing, and hence biofilm porosity; varying the density in space or time can prove difficult. This may prove superior for young biofilms with no cavities, whereas the cellular automata models may be better for aged biofilms. Incorporating cell to cell signaling via molecular exchange (e.g., quorum sensing) remains a challenge for both types of models.

Radu et al. [194] developed a two-dimensional model that incorporates fluid dynamics, mass transfer, biofilm properties, and geometric characteristics of a spiral-wound RO membrane. They attempted to incorporate interactions between fluid flow, biofilm growth, feed composition, and system configuration. Fluid flow was modeled using the Navier-Stokes equation while advection dispersion relationships determined the transport of solute and substrate compounds. Monod kinetics were employed for biofilm growth, and biomass accumulation, transport and sloughing were modeled using a cellular automata algorithm. Their model provided a reasonable approximation of the effects of biofouling on flux loss, pressure drop increase over time, and decline in salt rejection. The model was able to corroborate previous data on the effects of spacer geometry in laminar flow, and flux decline due to biofilm-enhanced concentration polarization during desalination of brackish water. 
Numerical and mathematical models have helped reveal details about the underlying mechanisms of biofouling. For example, increasing feed salinity generally leads to more pronounced concentration polarization effects, but associated changes in biofilm permeability can result in negligible drop in permeate flux [195]. Three-dimensional models can also be constructed for a more explicit representation of biofilm growth inside membrane modules [196]. Lastly, combined fouling models may become particularly useful because biofouling may occur in parallel with scaling and may enhance mineral precipitation [197].

\section{Post Treatment}

Reverse osmosis permeate is generally slightly acidic, has low alkalinity and buffering capacity, and has low concentration of hardness minerals calcium and magnesium [198]. Posttreatment is needed to protect human health, protect downstream infrastructure, and support downstream uses; specifically to 1) disinfect the water and maintain a disinfectant residual; 2) reduce the aggressiveness of the produced water relative to metal corrosion and concrete dissolution; 3) provide sufficient mineral content (calcium and magnesium) to protect human health, and to sustain agriculture and horticultural uses; and, 4) provide sufficient alkalinity to support downstream wastewater treatment [198]. Removal of boron may be addressed through plants design [199, 200]. (e.g., membrane selection, multiple passes with $\mathrm{pH}$ adjustment) or through post treatment.

RO permeate is readily disinfected because they contain a low microbial load, low total organic carbon concentration, and low particle content [201]. Turbidity of RO permeate is low, and inorganic turbidity introduced by remineralization does not interfere with disinfection by chlorine [201]. Although potential passage of viruses through some RO membranes may be a consideration, viruses can be readily inactivated using low doses of chlorine and short contact times ( $\mathrm{C} \times \mathrm{t}$ values). The aggressiveness of $\mathrm{RO}$ permeate is reduced primarily through $\mathrm{pH}$ adjustment, alkalinity addition, and adjusting the water chemistry through remineralization so there is a tendency to precipitate calcium chloride [199, 202]. Based on a review of the literature, utility surveys, and case study reviews, Duranceau et al. [203] recommended the goals presented in Table 2, including a $\mathrm{pH}$ range of 6.5 to 9.5 for seawater RO permeate.

Table 2. Desalination Post Treatment Water Quality Goals. Used with permission from [203].

\begin{tabular}{lcc} 
Parameter & Seawater & Brackish water \\
\hline $\mathrm{pH}$ & $6.5-9.5$ & $7.5-8.4$ \\
Alkalinity $\left(\mathrm{mg} / \mathrm{L}\right.$ as $\left.\mathrm{CaCO}_{3}\right)$ & $50-125$ & $75-150$ \\
Hardness $\left(\mathrm{mg} / \mathrm{L}\right.$ as $\left.\mathrm{CaCO}_{3}\right)$ & $50-85$ & $75-110$ \\
Calcium concentration $(\mathrm{mg} / \mathrm{L})$ & $50-75$ & $60-100$ \\
TDS $(\mathrm{mg} / \mathrm{L})$ & $100-500$ & $85-350$ \\
Sulfate to chloride ratio & $1-1.3$ & $0.5-1$ \\
Turbidity $(\mathrm{NTU})$ & $0.6-3$ & $0.2-2$ \\
Boron & $0.5-1$ & NA \\
\hline
\end{tabular}

The State of Israel requires a narrower range, 7.5 to 8.3 for desalinated water, and the World Health Organization recommends $\mathrm{pH}<8$ because higher values reduce the efficiency of 
chlorine disinfection [201]. Several researchers have found that corrosion and release of corrosion products can be reduced by maintaining sufficient alkalinity. Alkalinity is measured as the titration of basic species to the carbonic acid endpoint (about pH 4.5). In terms of carbonate species, which are usually predominant, it is defined as:

$$
\text { Alkalinity }\{\text { meq } / \mathrm{L}\}=2\left[\mathrm{CO}_{3}^{2-}\right]+\left[\mathrm{HCO}_{3}^{-}\right]+\left[\mathrm{OH}^{-}\right]-\left[\mathrm{H}^{+}\right]
$$

Carbonate alkalinity is an important component of buffer capacity or intensity, $\beta$, which quantifies the relationship between the change in $\mathrm{pH}$ and the change in concentration of strong acid or base, $C_{b}$ :

$$
\beta=\frac{d C_{b}}{d p H}=\frac{2.3 C_{T} K_{a 1}\left[\mathrm{H}^{+}\right]}{\left(K_{a 1}+\left[\mathrm{H}^{+}\right]\right)^{2}}+\frac{2.3 C_{T} K_{a 2}\left[\mathrm{H}^{+}\right]}{\left(K_{a 2}+\left[\mathrm{H}^{+}\right]\right)^{2}}+2.3\left(\left[\mathrm{H}^{+}\right]+\left[\mathrm{OH}^{-}\right]\right)
$$

Where $C_{T}$ is the total concentration of carbonate species, which can be estimated from measurements of alkalinity and $\mathrm{pH}$, and $K_{a}$ values are the acid dissociation constants for carbonic acid $\left(\mathrm{H}_{2} \mathrm{CO}_{3}{ }^{*}, K_{\mathrm{a} 1}\right)$ and bicarbonate $\left(\mathrm{HCO}_{3}{ }^{-}, K_{\mathrm{a} 2}\right)$. A buffer intensity greater than 0.5 milliequivalents per $\mathrm{pH}$ unit has been cited as indicative of a balanced, stabilized source water [203]. Alkalinity and resulting buffer capacity resist $\mathrm{pH}$ changes during subsequent treatment, blending, and distribution. Examples of processes that can potentially affect $\mathrm{pH}$ values include fluoridation with fluorosilicic acid $\left(\mathrm{H}_{2} \mathrm{SiF}_{6}\right)$ and chlorination by chlorine gas:

$$
\mathrm{Cl}_{2}+\mathrm{H}_{2} \mathrm{O} \rightarrow \mathrm{H}^{+}+\mathrm{Cl}^{-}+\mathrm{HOCl}
$$

Imran et al. [204] found that release of corrosion products from unlined cast iron and galvanized iron pipes (red water release) had a strong negative correlation with alkalinity, except when water was high in chloride and sulfate. A similar correlation with both $\mathrm{Fe}$ and $\mathrm{Mn}$ was found for UK waters [205]. As a result, Imran et al. [204] recommend maintaining alkalinity concentrations above $80 \mathrm{mg} / \mathrm{L}$ of $\mathrm{CaCO}_{3}$, a value that is reflected in the State of Israel Public Health Regulations [206].

Sontheimer et al. [207] proposed a Siderite model for the formation of corrosion resistant scales. Dense protective layers and low corrosion rates resulted when buffer intensity was high and $\mathrm{pH}<8.5$, conditions that favored the reaction of corrosion product $\mathrm{Fe}^{2+}$ and carbonate, $\mathrm{CO}_{3}{ }^{2-}$, to form Siderite, over the direct oxidation of $\mathrm{Fe}^{2+}$ to ferric oxides. However, Siderite was not required to be a constituent of the protective layer, which may form from subsequent Siderite oxidation to, e.g., Magnetite $\left(\mathrm{Fe}_{3} \mathrm{O}_{4}(\mathrm{~s})\right)$. Also, the presence of calcium and the formation of some calcite was necessary, so it is likely that the protective scale was a mixed precipitate. 
Alkalinity may also be required for downstream processes, such as wastewater treatment or water reclamation. For example, when biological ammonia nitrification is required, alkalinity is consumed [208]:

$$
\begin{aligned}
& \mathrm{NH}_{4}^{+}+2 \mathrm{O}_{2} \rightarrow \mathrm{NO}_{3}^{-}+2 \mathrm{H}^{+}+\mathrm{H}_{2} \mathrm{O} \\
& 2 \mathrm{H}^{+}+2 \mathrm{HCO}_{3}^{-} \rightarrow 2 \mathrm{H}_{2} \mathrm{CO}_{3}
\end{aligned}
$$

McNeill and Edwards note that precipitation of a thin layer of calcium carbonate (calcite) was the earliest proposed method to control iron corrosion [209], and Delion et al. [199] recommend that to protect distribution networks and equipment, water should be slightly scale forming to create a protective coat on internal surfaces. For this reason, many different indices related to calcium carbonate stability have been developed and promoted [199]. Although still used [202], the Langlier Index does not provide an effective means of controlling iron corrosion, and other calcite indices have only limited use in corrosion control [209]. Still, Birnhack et al. [198] recommend the calcium carbonate precipitation potential $\left(\mathrm{CCPP}, \mathrm{mg} / \mathrm{L}\right.$ as $\left.\mathrm{CaCO}_{3}\right)$ as a quantitative and unambiguous parameter; values $3<\mathrm{CCPP}<10$ are recommended to decrease the rate of corrosion and reduce red water events, as reflected in the State of Israel Health Regulations.

The World Health Organization (WHO) has recommended that remineralizing RO permeate with calcium and magnesium salts should be considered from a strictly health point of view in some cases, especially where there is evidence of a dietary deficiency of calcium and magnesium, and where a supply is moving from a source that has significant levels of calcium and magnesium to low-mineral desalinated water [201]. This relates primarily to the potentially beneficial effects of magnesium in preventing some types of heart disease, association between magnesium deficiency and metabolic syndrome, indicating a pre-diabetic condition, and beneficial effects of calcium in reducing osteoporosis risk.

Insufficient calcium and magnesium concentrations can result in downstream reclaimed water that is high in sodium and not suitable for agricultural purposes, especially in arid regions where precipitation is low and reclaimed water makes up a high fraction of the total water supply. The sodium hazard associated with an irrigation water supply is quantified by the sodium absorption ratio, given as

$$
S A R=\frac{\left[\mathrm{Na}^{+}\right]}{\sqrt{\left[\mathrm{Ca}^{2+}\right]+\left[\mathrm{Mg}^{2+}\right]}}
$$


Where species in brackets indicate molar concentrations. Irrigation waters having high SAR levels can lead to the build-up of high sodium levels and displacement of calcium and magnesium, leading to soil dispersion, a loss of soil structure, lowering of infiltration and percolation rates, soil crusting, poor seedling emergence, and poor aeration [210].

Polyphosphate offers benefits for preventing scaling and precipitation of iron or manganese and facilitating certain types of iron corrosion control, but is not recommended for lead corrosion control [211]. Utilities were advised to determine the minimum polyphosphate dose that achieves iron corrosion control, in order to minimize residual polyphosphate. This is because the maximum soluble lead concentrations in pipes during stagnation are proportional to this residual value.

\section{Conclusions and Future Prospects}

Although reverse osmosis is now the method of choice for desalination of seawater to portable water, its application has been mainly in in arid regions (e.g., Israel and the Gulf) due to its relatively high cost. We demonstrate in this review that opportunities exist to reduce the cost of RO desalination by emphasizing pretreatment, fouling and post treatment. Recent focus on the RO process and associated equipment have reduced the energy consumption from 15 to $\sim 2$ $\mathrm{kWh} / \mathrm{m}^{3}$ over the past 25 years. This excludes the energy required for intake, pretreatment, posttreatment and brine discharge. Clearly reducing this energy consumption further will require enormous effort. Several mitigating strategies to reduce fouling are reviewed, especially in light of the 'three legs", or major parameters that govern all membrane processes: (i) selectivity, (ii) permeability, and (iii) concentration polarization and fouling. These include operational and membrane module-related approaches. Thus, pretreatment and cleaning is essential for mainlining high performance, while surface chemical modification, module design for optimal fluid mechanics and mass transfer offer orthogonal ways to reduce fouling. New computational methods, such as molecular simulation of fouling, and for seeking optimal fluid mechanics and mass transfer, inter membrane spacer design and its effects on reducing fouling, and particle trajectory analysis for predicting and reducing fouling.

Further technical advances will require a deeper understanding of the fundamental science underlying pretreatment, fouling and post-treatment. Extensive use of fouling models will help identify the likely type and cause of fouling.

\section{Acknowledgements}

GB acknowledges financial support (i) originally from the Office of Saline Water, Department of The Interior that helped start his research career in synthetic membranes, (ii) from the US National Science Foundation and the US Department of Energy for long-term funding of his research group, (iii) Francois Fiessinger, Lyonnaise des Eaux, Le Pecq, France for practical insight in water matters, (iv) Caleb Funk, Dow Water \& Process Solutions, for providing samples of RO membrane spacers, (v) Howard. P. Isermann for supporting the graduate students, 
and (vi) RPI for GB's chair endowment. He is also indebted to K. S. Spiegler and Ora Kedem for their support and wise guidance during the early part of his career in membrane filtration. Finally, he thanks all his past students, post-docs and visiting professors for their contributions and for teaching him about research and membrane filtration. 


\section{References}

[1] A.N. Other, Beyond Scarcity: Power, Poverty and the Global Water Crisis. , in: United Nations Development Programme. 2006; Human Development Report 2006, New York, 2006.

[2] G. Wade Miller, Integrated concepts in water reuse: managing global water needs, Desalination, 187 (2006) 65-75.

[3] N. Ghaffour, T.M. Missimer, G.L. Amy, Technical review and evaluation of the economics of water desalination: current and future challenges for better water supply sustainability, Desalination, 309 (2013) 197-207.

[4] M. Elimelech, W.A. Phillip, The future of seawater desalination: energy, technology, and the environment, Science, 333 (2011) 712-717.

[5] http://idadesal.org/desalination-101/desalination-by-the-numbers/, in.

[6] Industrial Desalination and Water Reuse: ultrapure water, challenging waste streams and improved water efficiency, IDA, in, 2013.

[7] T. Pankratz, MEDRC workshop on Membrane Technology Used in Desalination and Wastewater Treatment for Reuse, Muscat, Oman, March, (2008).

[8] J. Grimaldi, J. Imbrogno, J. Kilduff, G. Belfort, A new class of synthetic membranes: Organophilic pervaporation brushes for organics recovery, Chemistry of Materials, (2015). [9] L. Song, J. Hu, S. Ong, W. Ng, M. Elimelech, M. Wilf, Emergence of thermodynamic restriction and its implications for full-scale reverse osmosis processes, Desalination, 155 (2003) 213-228.

[10] M. Wilf, Design consequences of recent improvements in membrane performance, Desalination, 113 (1997) 157-163.

[11] A. Zhu, P.D. Christofides, Y. Cohen, Effect of thermodynamic restriction on energy cost optimization of RO membrane water desalination, Industrial \& engineering chemistry research, 48 (2008) 6010-6021.

[12] G.M. Geise, D.R. Paul, B.D. Freeman, Fundamental water and salt transport properties of polymeric materials, Progress in Polymer Science, 39 (2014) 1-42.

[13] F. Zamani, J.W. Chew, E. Akhondi, W.B. Krantz, A.G. Fane, Unsteady-state shear strategies to enhance mass-transfer for the implementation of ultrapermeable membranes in reverse osmosis: A review, Desalination, 356 (2015) 328-348.

[14] A.K. Plappally, J.H. Lienhard V, Energy requirements for water production, treatment, end use, reclamation, and disposal, Renewable and Sustainable Energy Reviews, 16 (2012) 48184848.

[15] R. Semiat, Energy Issues in Desalination Processes, Environmental Science \& Technology, 42 (2008) 8193-8201.

[16] J. Zhou, V.W.-C. Chang, A.G. Fane, Life Cycle Assessment for Desalination: A Review on Methodology Feasibility and Reliability, Water research, (2014).

[17] R. Das, M.E. Ali, S.B. Abd Hamid, S. Ramakrishna, Z.Z. Chowdhury, Carbon nanotube membranes for water purification: A bright future in water desalination, Desalination, 336 (2014) 97-109.

[18] F. Perreault, A.F. de Faria, M. Elimelech, Environmental applications of graphene-based nanomaterials, Chemical Society Reviews, 44 (2015) 5861-5896.

[19] F. Helfer, C. Lemckert, Y.G. Anissimov, Osmotic power with Pressure Retarded Osmosis: Theory, performance and trends - A review, Journal of Membrane Science, 453 (2014) 337-358. [20] R.V. Linares, Z. Li, S. Sarp, S.S. Bucs, G. Amy, J.S. Vrouwenvelder, Forward osmosis niches in seawater desalination and wastewater reuse, Water research, 66 (2014) 122-139. 
[21] A.G. Fane, R. Wang, M.X. Hu, Synthetic Membranes for Water Purification: Status and Future, Angew. Chem.-Int. Edit., 54 (2015) 3368-3386.

[22] A. Subramani, J.G. Jacangelo, Emerging desalination technologies for water treatment: A critical review, Water research, 75 (2015) 164-187.

[23] T. Humplik, J. Lee, S. O’Hern, B. Fellman, M. Baig, S. Hassan, M. Atieh, F. Rahman, T. Laoui, R. Karnik, Nanostructured materials for water desalination, Nanotechnology, 22 (2011) 292001.

[24] G.M. Geise, H.S. Lee, D.J. Miller, B.D. Freeman, J.E. McGrath, D.R. Paul, Water Purification by Membranes: The Role of Polymer Science, Journal of Polymer Science Part BPolymer Physics, 48 (2010) 1685-1718.

[25] L.F. Greenlee, D.F. Lawler, B.D. Freeman, B. Marrot, P. Moulin, Reverse osmosis desalination: Water sources, technology, and today's challenges, Water Research, 43 (2009) 2317-2348.

[26] Y.H. La, J. Diep, R. Al-Rasheed, D. Miller, L. Krupp, G.M. Geise, A. Vora, B. Davis, M. Nassar, B.D. Freeman, M. McNeil, G. Dubois, Enhanced desalination performance of polyamide bi-layer membranes prepared by sequential interfacial polymerization, Journal of Membrane Science, 437 (2013) 33-39.

[27] T.C. Merkel, B.D. Freeman, R.J. Spontak, Z. He, I. Pinnau, P. Meakin, A.J. Hill, Ultrapermeable, reverse-selective nanocomposite membranes, Science, 296 (2002) 519-522. [28] T.C. Merkel, B.D. Freeman, R.J. Spontak, Z. He, I. Pinnau, P. Meakin, A.J. Hill, Sorption, transport, and structural evidence for enhanced free volume in poly(4-methyl-2-pentyne)/fumed silica nanocomposite membranes, Chemistry of Materials, 15 (2003) 109-123.

[29] J.E. Cadotte =, Petersen R. J., Larson R. E., and Erickson E. E., Desalination, 32 (1980).

[30] R.J. Petersen, COMPOSITE REVERSE-OSMOSIS AND NANOFILTRATION

MEMBRANES, Journal of Membrane Science, 83 (1993) 81-150.

[31] C.A. Smolders, A.J. Reuvers, R.M. Boom, I.M. Wienk, MICROSTRUCTURES IN PHASE-INVERSION MEMBRANES .1. FORMATION OF MACROVOIDS, Journal of Membrane Science, 73 (1992) 259-275.

[32] P. vandeWitte, P.J. Dijkstra, J.W.A. vandenBerg, J. Feijen, Phase separation processes in polymer solutions in relation to membrane formation, Journal of Membrane Science, 117 (1996) $1-31$.

[33] M. Kurihara, Hanakawa, M., Mega-ton Water System: Japanese national research and development project on seawater desalination and wastewater reclamation Desalination, 308 (2013) 7.

[34] H.S.I. Lee, S. J.. Kim, J. H. Kim, H. J.. Kim,J. P.. Min, B. R., Polyamide thin-film nanofiltration membranes containing TiO2 nanoparticles, Desalination, 219 (2008) 9.

[35] S.K. Lee, H. Patel, R. Im, S Kim, L. Min, B. , Silver nanoparticles immobilized on thin film composite polyamide membrane: Characterization, nanofiltration, antifouling properties, Polym. Adv. Technol., 18 (2007) 7.

[36] B.H.H. Jeong, E. M. V.,.Yan,Y. S..Subramani,A..Huang, X. F..Hurwitz,G.,.Ghosh, A. K., Jawor, A., Interfacial polymerization of thin film nanocomposites: a new concept for reverse osmosis membranes, J. Membr. Sci. , 294 (2007) 8.

[37] M.-T.M. Pendergast, Ghosh, A. K., Hoek, E,.M.V., Separation performance and interfacial properties of nanocomposite reverse osmosis membranes, Desalination, 308 (2013) 6.

[38] A.G. Livingston, Metal Organic Frameworks (MOFs) in Membranes for Organic Solvent Nanofiltration., in: 2014 Annual NAMS Confernce, Houston, TX, 2014. 
[39] P. Agre, L.S. King, M. Yasui, W.B. Guggino, O.P. Ottersen, Y. Fujiyoshi, A. Engel, S. Nielsen, Aquaporin water channels--from atomic structure to clinical medicine, The Journal of physiology, 542 (2002) 3-16.

[40] C. Peter, G. Hummer, Ion transport through membrane-spanning nanopores studied by molecular dynamics simulations and continuum electrostatics calculations, Biophysical journal, 89 (2005) 2222-2234.

[41] J.K. Holt, H.G. Park, Y. Wang, M. Stadermann, A.B. Artyukhin, C.P. Grigoropoulos, A. Noy, O. Bakajin, Fast mass transport through sub-2-nanometer carbon nanotubes, Science, 312 (2006) 1034-1037.

[42] L. Liu, S. Ryu, M.R. Tomasik, E. Stolyarova, N. Jung, M.S. Hybertsen, M.L. Steigerwald, L.E. Brus, G.W. Flynn, Graphene oxidation: thickness-dependent etching and strong chemical doping, Nano Lett, 8 (2008) 1965-1970.

[43] R.R. Nair, H.A. Wu, P.N. Jayaram, I.V. Grigorieva, A.K. Geim, Unimpeded permeation of water through helium-leak-tight graphene-based membranes, Science, 335 (2012) 442-444.

[44] B.C. Robertson, A.L. Zydney, PROTEIN ADSORPTION IN ASYMMETRIC ULTRAFILTRATION MEMBRANES WITH HIGHLY CONSTRICTED PORES, Journal of Colloid and Interface Science, 134 (1990) 563-575.

[45] A. Matin, Z. Khan, S.M.J. Zaidi, M.C. Boyce, Biofouling in reverse osmosis membranes for seawater desalination: Phenomena and prevention, Desalination, 281 (2011) 1-16.

[46] M. Vert, Y. Doi, K.-H. Hellwich, M. Hess, P. Hodge, P. Kubisa, M. Rinaudo, F. Schué, Terminology for biorelated polymers and applications (IUPAC Recommendations 2012), Pure and Applied Chemistry, 84 (2012).

[47] P.V. Bhaskar, N.B. Bhosle, Microbial extracellular polymeric substances in marine biogeochemical processes, Current Science, 88 (2005) 45-53.

[48] C. Dreszer, J.S. Vrouwenvelder, A.H. Paulitsch-Fuchs, A. Zwijnenburg, J.C. Kruithof, H.C. Flemming, Hydraulic resistance of biofilms, Journal of Membrane Science, 429 (2013) 436-447. [49] H. Ridgway, K. Ishida, G. Rodriguez, J. Safarik, T. Knoell, R. Bold, Biofouling of membranes: Membrane preparation, characterization, and analysis of bacterial adhesion, Methods in enzymology, 310 (1999) 463-494.

[50] H.C. Flemming, G. Schaule, R. McDonogh, Biofouling on membranes. A short review, Biofilms-Science and Technology, (1992) 487-497.

[51] R.a.n. Chmielewski, J.f. Frank, Biofilm Formation and Control in Food Processing Facilities, Comprehensive Reviews in Food Science and Food Safety, 2 (2003) 22-32.

[52] J.D. Bryers, B.D. Ratner, Bioinspired implant materials befuddle bacteria, ASM NewsAmerican Society for Microbiology, 70 (2004) 232-232.

[53] J.S. Baker, L.Y. Dudley, Biofouling in membrane systems - A review, Desalination, 118 (1998) 81-89.

[54] M.T. Khan, P.Y. Hong, N. Nada, J.P. Croue, Does chlorination of seawater reverse osmosis membranes control biofouling?, WATER RESEARCH, 78 (2015) 84-97.

[55] R. McDonogh, G. Schaule, H.C. Flemming, THE PERMEABILITY OF BIOFOULING LAYERS ON MEMBRANES, JOURNAL OF MEMBRANE SCIENCE, 87 (1994) 199-217. [56] J. Mallevialle, P.E. Odendaal, M.R. Wiesner, Water treatment membrane processes, American Water Works Association, 1996.

[57] K.R. Zodrow, M.E. Tousley, M. Elimelech, Mitigating biofouling on thin-film composite polyamide membranes using a controlled-release platform, Journal of Membrane Science, 453 (2014) 84-91. 
[58] J.S. Vrouwenvelder, J.A.M. van Paassen, J.M.C. van Agtmaal, M.C.M. van Loosdrecht, J.C. Kruithof, A critical flux to avoid biofouling of spiral wound nanofiltration and reverse osmosis membranes: Fact or fiction?, Journal of Membrane Science, 326 (2009) 36-44.

[59] W.S. Guo, H.H. Ngo, J.X. Li, A mini-review on membrane fouling, Bioresource Technology, 122 (2012) 27-34.

[60] J.S. Vrouwenvelder, S.A. Manolarakis, H.R. Veenendaal, D. van der Kooij, Biofouling potential of chemicals used for scale control in RO and NF membranes, Desalination, 132 (2000) $1-10$.

[61] A. Sweity, Y. Oren, Z. Ronen, M. Herzberg, The influence of antiscalants on biofouling of RO membranes in seawater desalination, Water Research, 47 (2013) 3389-3398.

[62] S. Bason, I. David, A. Shulman, M. Priel, The use of phosphorus-free antiscalants in BWRO desalination plants and brine disposal pipelines, DESALINATION AND WATER TREATMENT, 55 (2015) 3498-3505.

[63] J.S. Vrouwenvelder, S.A. Manolarakis, J.P. van der Hoek, J.A.M. van Paassen, W.G.J. van der Meer, J.M.C. van Agtmaal, H.D.M. Prummel, J.C. Kruithof, M.C.M. van Loosdrecht, Quantitative biofouling diagnosis in full scale nanofiltration and reverse osmosis installations, Water Research, 42 (2008) 4856-4868.

[64] R. Reed, G. Belfort, Characterization of fouling potential for pressure-driven membrane processes: a new simulated flow cell, Water Sci. Technol., 14 (1982) 499-522.

[65] E.I. Prest, M. Staal, M. Kühl, M.C.M. van Loosdrecht, J.S. Vrouwenvelder, Quantitative measurement and visualization of biofilm $\mathrm{O} 2$ consumption rates in membrane filtration systems, Journal of Membrane Science, 392-393 (2012) 66-75.

[66] J.S. Vrouwenvelder, Biofouling of spiral wound membrane systems, TU Delft, Delft University of Technology, 2009.

[67] S. Jeong, L.H. Kim, S.J. Kim, T.V. Nguyen, S. Vigneswaran, I.S. Kim, Biofouling Potential Reductions Using a Membrane Hybrid System as a Pre-treatment to Seawater Reverse Osmosis, Appl. Biochem. Biotechnol., 167 (2012) 1716-1727.

[68] F. Macedonio, E. Drioli, A. Gusev, A. Bardow, R. Semiat, M. Kurihara, Efficient technologies for worldwide clean water supply, Chemical Engineering and Processing: Process Intensification, 51 (2012) 2-17.

[69] B. Durham, M.M. Bourbigot, T. Pankratz, Membranes as pretreatment to desalination in wastewater reuse: operating experience in the municipal and industrial sectors, Desalination, 138 (2001) 83-90.

[70] W. Lau, P. Goh, A. Ismail, S. Lai, Ultrafiltration as a pretreatment for seawater desalination: A review, MEMBRANE WATER TREATMENT, 5 (2014) 15-29.

[71] F. Knops, S. van Hoof, H. Futselaar, L. Broens, Economic evaluation of a new ultrafiltration membrane for pretreatment of seawater reverse osmosis, Desalination, 203 (2007) 300-306. [72] J. Suarez, B. Salgado, A. Casanas, J.C. Gonzalez, J. Pordomingo, One-year operational experience with ultrafiltration as pretreatment of seawater reverse osmosis desalination system (Maspalomas-I Plant), DESALINATION AND WATER TREATMENT, 55 (2015) 2813-2821. [73] M. Dixon, V. Ayala, G. Hijos, C. Pelekani, Experiences from the Adelaide Desalination project: ultrafiltration cleaning optimisation-from pilot to full-scale operation, DESALINATION AND WATER TREATMENT, 51 (2013) 397-406.

[74] P.Y. Hong, N. Moosa, J. Mink, Dynamics of microbial communities in an integrated ultrafiltration-reverse osmosis desalination pilot plant located at theArabian Gulf, DESALINATION AND WATER TREATMENT, 57 (2016) 16310-16323. 
[75] A. Brehant, V. Bonnelye, M. Perez, Comparison of MF/UF pretreatment with conventional filtration prior to RO membranes for surface seawater desalination, Desalination, 144 (2002) 353-360.

[76] Y.M. Kim, S.J. Kim, Y.S. Kim, S. Lee, I.S. Kim, J.H. Kim, Overview of systems engineering approaches for a large-scale seawater desalination plant with a reverse osmosis network, Desalination, 238 (2009) 312-332.

[77] S. Liyanaarachchi, L. Shu, S. Muthukumaran, V. Jegatheesan, K. Baskaran, Problems in seawater industrial desalination processes and potential sustainable solutions: a review, Reviews in Environmental Science and Bio/Technology, 13 (2014) 203-214.

[78] N.N. Li, A.G. Fane, W.W. Ho, T. Matsuura, Advanced membrane technology and applications, John Wiley \& Sons, 2011.

[79] N. Voutchkov, Considerations for selection of seawater filtration pretreatment system, Desalination, 261 (2010) 354-364.

[80] H. Ltd., Product bulletin - Kristal UF membrane, in, 2013.

[81] J.J. Kim, H. Yoon, J. Hong, T. Lee, M. Wilf, Evaluation of new compact pretreatment system for high turbidity seawater: Fiber filter and ultrafiltration, Desalination, 313 (2013) 28-35. [82] J. Zhang, S. Gao, H. Zeng, F. Zhang, C. Li, Y. Liu, D. Fu, C. Ye, Pilot testing of two insideout UF modules prior to RO for highturbidity seawater desali, Desalination, 196 (2006) 66-75. [83] L.X. Gao, A. Rahardianto, H. Gu, P.D. Christofides, Y. Cohen, Novel design and operational control of integrated ultrafiltration - Reverse osmosis system with RO concentrate backwash, Desalination, 382 (2016) 43-52.

[84] T. Al-Sarkal, H.A. Arafat, Ultrafiltration versus sedimentation-based pretreatment in Fujairah-1 RO plant: Environmental impact study, Desalination, 317 (2013) 55-66.

[85] G. Pearce, SWRO pre-treatment: Cost and sustainability, Filtration \& Separation, 47 (2010) 36-38.

[86] H. Basri, A. Ismail, M. Aziz, Polyethersulfone (PES)-silver composite UF membrane: effect of silver loading and PVP molecular weight on membrane morphology and antibacterial activity, Desalination, 273 (2011) 72-80.

[87] H. Basri, A. Ismail, M. Aziz, Microstructure and anti-adhesion properties of PES/TAP/Ag hybrid ultrafiltration membrane, Desalination, 287 (2012) 71-77.

[88] M. Hoang, B. Bolto, C. Haskard, O. Barron, S. Gray, G. Leslie, Desalination in Australia, CSIRO Water for a Health Country, 2009.

[89] NCED, Australian desalination research road map, National Center of Excellence in Desalination, in, 2010.

[90] A.S. Al-Amoudi, A.M. Farooque, Performance restoration and autopsy of NF membranes used in seawater pretreatment, Desalination, 178 (2005) 261-271.

[91] T. Osta, L. Bakheet Sr, Pretreatment system in reverse osmosis plants, Desalination, 63 (1987) 71-80.

[92] A.G. Fane, Proc., Symposium on Characterization of Polymers with Surface, Lappeenranta, Finland, p. 51, in, 1997.

[93] M.H. Tran-Ha, D.E. Wiley, The relationship between membrane cleaning efficiency and water quality, Journal of Membrane Science, 145 (1998) 99-110.

[94] M. Goosen, S. Sablani, H. Al-Hinai, S. Al-Obeidani, R. Al-Belushi, D. Jackson, Fouling of reverse osmosis and ultrafiltration membranes: a critical review, Separation Science and Technology, 39 (2005) 2261-2297.

[95] G. Belfort, Advanced Membrane Concepts Class Notes, RPI Graduate Course, in. 
[96] J. Lindau, A.-S. Jönsson, Cleaning of ultrafiltration membranes after treatment of oily waste water, Journal of Membrane Science, 87 (1994) 71-78.

[97] G. Daufin, U. Merin, J. Labbe, A. Quemerais, F. Kerhervé, Cleaning of inorganic

membranes after whey and milk ultrafiltration, Biotechnol. Bioeng., 38 (1991) 82-89.

[98] H.F. Bohner, R.L. Bradley Jr, Effective Cleaning and Sanitizing of Polysulfone

Ultrafiltration Membrane Systems, J. Dairy Sci., 75 (1992) 718-724.

[99] W.D. Mores, R.H. Davis, Direct observation of membrane cleaning via rapid backpulsing, Desalination, 146 (2002) 135-140.

[100] Y. Cohen, P.D. Christofides, A. Rahardianto, A.R. Bartman, A. Zhu, H. Gu, L.X. Gao, Apparatus, system and method for integrated filtration and reverse osmosis desalination, in, US 13/822,622, 2011.

[101] H. Mallubhotla, G. Belfort, Semiempirical modeling of cross-flow microfiltration with periodic reverse filtration, Industrial \& engineering chemistry research, 35 (1996) 2920-2928. [102] H.-C. Flemming, Biofouling in water systems-cases, causes and countermeasures, Appl. Microbiol. Biotechnol., 59 (2002) 629-640.

[103] H. Lee, G. Amy, J. Cho, Y. Yoon, S.-H. Moon, I.S. Kim, Cleaning strategies for flux recovery of an ultrafiltration membrane fouled by natural organic matter, Water research, 35 (2001) 3301-3308.

[104] G. Morel, N. Ouazzani, A. Graciaa, J. Lachaise, Surfactant modified ultrafiltration for nitrate ion removal, Journal of Membrane Science, 134 (1997) 47-57.

[105] C. Whittaker, H. Ridgway, B. Olson, Evaluation of cleaning strategies for removal of biofilms from reverse-osmosis membranes, Applied and environmental microbiology, 48 (1984) 395-403.

[106] S. Siavash Madaeni, T. Mohamamdi, M. Kazemi Moghadam, Chemical cleaning of reverse osmosis membranes, Desalination, 134 (2001) 77-82.

[107] E. Roth, M. Kessler, B. Fabre, A. Accary, Sodium chloride stimulus-response experiments in spiral wound reverse osmosis membranes: a new method to detect fouling, Desalination, 121 (1999) 183-193.

[108] A.F. Ammerlaan, J. Franklin, C. Moody, Yuma desalting plant. Membrane degradation during test operations, Desalination, 88 (1992) 33-49.

[109] M. Gu, A.J. Vegas, D.G. Anderson, R.S. Langer, J.E. Kilduff, G. Belfort, Combinatorial synthesis with high throughput discovery of protein-resistant membrane surfaces, Biomaterials, 34 (2013) 6133-6138.

[110] M. Gu, J.E. Kilduff, G. Belfort, High throughput atmospheric pressure plasma-induced graft polymerization for identifying protein-resistant surfaces, Biomaterials, 33 (2012) 12611270.

[111] P.S. Yune, J.E. Kilduff, G. Belfort, Searching for novel membrane chemistries: Producing a large library from a single graft monomer at high throughput, Journal of Membrane Science, 390 (2012) 1-11.

[112] P.S. Yune, J.E. Kilduff, G. Belfort, Using co-solvents and high throughput to maximize protein resistance for poly (ethylene glycol)-grafted poly (ether sulfone) UF membranes, Journal of Membrane Science, 370 (2011) 166-174.

[113] J. Imbrogno, M.D. Williams, G. Belfort, A New Combinatorial Method to Synthesize, Screen, and Discover Anti-Fouling Surface Chemistries, ACS applied materials \& interfaces, 7 (2015) 2385-2392. 
[114] M. Zhou, H. Liu, J.E. Kilduff, R. Langer, D.G. Anderson, G. Belfort, High Throughput Synthesis and Screening of New Protein Resistant Surfaces for Membrane Filtration, AIChE journal, 56 (2010) 1932-1945.

[115] G.-R. Xu, J.-N. Wang, C.-J. Li, Strategies for improving the performance of the polyamide thin film composite (PA-TFC) reverse osmosis (RO) membranes: Surface modifications and nanoparticles incorporations, Desalination, 328 (2013) 83-100.

[116] B.M. Steels, J. Koska, C.A. Haynes, Analysis of brush-particle interactions using selfconsistent-field theory, Journal of Chromatography B: Biomedical Sciences and Applications, 743 (2000) 41-56.

[117] B.D. McCloskey, H.B. Park, H. Ju, B.W. Rowe, D.J. Miller, B.D. Freeman, A bioinspired fouling-resistant surface modification for water purification membranes, Journal of Membrane Science, 413-414 (2012) 82-90.

[118] L.-P. Zhu, Y.-Y. Xu, X.-Z. Wei, B.-K. Zhu, Hydrophilic modification of poly(phthalazine ether sulfone ketone) ultrafiltration membranes by the surface immobilization of poly(ethylene glycol) acrylates, Desalination, 242 (2009) 96-109.

[119] S. Krishnan, C.J. Weinman, C.K. Ober, Advances in polymers for anti-biofouling surfaces, Journal of Materials Chemistry, 18 (2008) 3405-3413.

[120] D.R. Dreyer, D.J. Miller, B.D. Freeman, D.R. Paul, C.W. Bielawski, Elucidating the Structure of Poly(dopamine), Langmuir, 28 (2012) 6428-6435.

[121] H. Lee, S.M. Dellatore, W.M. Miller, P.B. Messersmith, Mussel-Inspired Surface Chemistry for Multifunctional Coatings, Science, 318 (2007) 426-430.

[122] S. Jiang, Z. Cao, Ultralow-Fouling, Functionalizable, and Hydrolyzable Zwitterionic Materials and Their Derivatives for Biological Applications, Advanced Materials, 22 (2010) 920-932.

[123] G. Cheng, G. Li, H. Xue, S. Chen, J.D. Bryers, S. Jiang, Zwitterionic carboxybetaine polymer surfaces and their resistance to long-term biofilm formation, Biomaterials, 30 (2009) 5234-5240.

[124] I.J. Roh, S.Y. Park, J. Kim, C. Kim, Effects of the polyamide molecular structure on the performance of reverse osmosis membranes, J. Polym. Sci., Part B: Polym. Phys., 36 (1998) 1821-1830.

[125] S.H. Son, J. Jegal, Preparation and characterization of polyamide reverse-osmosis membranes with good chlorine tolerance, J. Appl. Polym. Sci., 120 (2011) 1245-1252. [126] S. Hong, I.-C. Kim, T. Tak, Y.-N. Kwon, Interfacially synthesized chlorine-resistant polyimide thin film composite (TFC) reverse osmosis (RO) membranes, Desalination, 309 (2013) 18-26.

[127] G. Decher, Fuzzy Nanoassemblies: Toward Layered Polymeric Multicomposites, Science, 277 (1997) 1232-1237.

[128] G. Decher, J.D. Hong, J. Schmitt, Buildup of ultrathin multilayer films by a self-assembly process: III. Consecutively alternating adsorption of anionic and cationic polyelectrolytes on charged surfaces, Thin Solid Films, 210-211, Part 2 (1992) 831-835.

[129] X.-P. Jiang, S.L. Clark, P.T. Hammond, Side-by-side directed multilayer patterning using surface templates, Advanced Materials, 13 (2001) 1669.

[130] X. Jiang, P.T. Hammond, Selective Deposition in Layer-by-Layer Assembly: Functional Graft Copolymers as Molecular Templates, Langmuir, 16 (2000) 8501-8509. 
[131] D. Yoo, S.S. Shiratori, M.F. Rubner, Controlling bilayer composition and surface wettability of sequentially adsorbed multilayers of weak polyelectrolytes, Macromolecules, 31 (1998) 4309-4318.

[132] S.S. Shiratori, M.F. Rubner, pH-dependent thickness behavior of sequentially adsorbed layers of weak polyelectrolytes, Macromolecules, 33 (2000) 4213-4219.

[133] O. Sanyal, I. Lee, Recent Progress in the Applications of Layer-By-Layer Assembly to the Preparation of Nanostructured Ion-Rejecting Water Purification Membranes, Journal of nanoscience and nanotechnology, 14 (2014) 2178-2189.

[134] S.U. Hong, R. Malaisamy, M.L. Bruening, Optimization of flux and selectivity in $\mathrm{Cl}<$ sup $>-</$ sup $>/$ SO $<$ sub $>4</$ sub $><$ sup $>2-</$ sup $>$ separations with multilayer polyelectrolyte membranes, Journal of Membrane Science, 283 (2006) 366-372.

[135] R. Malaisamy, M.L. Bruening, High-flux nanofiltration membranes prepared by adsorption of multilayer polyelectrolyte membranes on polymeric supports, Langmuir, 21 (2005) 1058710592.

[136] S.U. Hong, R. Malaisamy, M.L. Bruening, Separation of Fluoride from Other Monovalent Anions Using Multilayer Polyelectrolyte Nanofiltration Membranes, Langmuir, 23 (2007) 17161722.

[137] W. Jin, A. Toutianoush, B. Tieke, Use of polyelectrolyte layer-by-layer assemblies as nanofiltration and reverse osmosis membranes, Langmuir, 19 (2003) 2550-2553.

[138] A. Toutianoush, W. Jin, H. Deligöz, B. Tieke, Polyelectrolyte multilayer membranes for desalination of aqueous salt solutions and seawater under reverse osmosis conditions, Appl. Surf. Sci., 246 (2005) 437-443.

[139] J. Park, J. Park, S.H. Kim, J. Cho, J. Bang, Desalination membranes from pH-controlled and thermally-crosslinked layer-by-layer assembled multilayers, Journal of Materials Chemistry, 20 (2010) 2085-2091.

[140] T. Ishigami, K. Amano, A. Fujii, Y. Ohmukai, E. Kamio, T. Maruyama, H. Matsuyama, Fouling reduction of reverse osmosis membrane by surface modification via layer-by-layer assembly, Separation and Purification Technology, 99 (2012) 1-7.

[141] G.-d. Kang, Y.-m. Cao, Development of antifouling reverse osmosis membranes for water treatment: a review, Water research, 46 (2012) 584-600.

[142] A.K. Dutta, G. Belfort, Interactions between polycationic and polyanionic layers: Changes in rigidity, charge and adsorption kinetics, Sensors and Actuators B: Chemical, 136 (2009) 60-65. [143] R. Mellis, W.N. Gill, G. Belfort, Fluid dynamics in a tubular membrane: theory and experiment, Chem. Eng. Commun., 122 (1993) 103-125.

[144] G. Belfort, R.H. Davis, A.L. Zydney, The behavior of suspensions and macromolecular solutions in crossflow microfiltration, Journal of Membrane Science, 96 (1994) 1-58.

[145] W. Dean, Fluid motion in a curved channel, Proceedings of the Royal Society of London.

Series A, Containing Papers of a Mathematical and Physical Character, 121 (1928) 402-420.

[146] M.E. Brewster, K.-Y. Chung, G. Belfort, Dean vortices with wall flux in a curved channel

membrane system: 1 . A new approach to membrane module design, Journal of Membrane

Science, 81 (1993) 127-137.

[147] K.Y. Chung, R. Bates, G. Belfort, Dean vortices with wall flux in a curved channel membrane system: 4 . Effect of vortices on permeation fluxes of suspensions in microporous membrane, Journal of Membrane Science, 81 (1993) 139-150. 
[148] K.Y. Chung, W.A. Edelstein, G. Belfort, Dean vortices with wall flux in a curved channel membrane system.: 6. Two dimensional magnetic resonance imaging of the velocity field in a curved impermeable slit, Journal of Membrane Science, 81 (1993) 151-162.

[149] K. Chung, W. Edelstein, X. Li, G. Belfort, Dean vortices in a curved channel membrane system: 5. Three dimensional magnetic resonance imaging and numerical analysis of the velocity field in a curved impermeable tube, AIChE J, 39 (1993) 1592.

[150] K.Y. Chung, M.E. Brewster, G. Belfort, Dean vortices with wall flux in a curved channel membrane system: 2 . The velocity field, AIChE Journal, 42 (1996) 347-358.

[151] H. Mallubhotla, G. Belfort, Flux enhancement during Dean vortex microfiltration. 8.

Further diagnostics, Journal of Membrane Science, 125 (1997) 75-91.

[152] H. Mallubhotla, S. Hoffmann, M. Schmidt, J. Vente, G. Belfort, Flux enhancement during dean vortex tubular membrane nanofiltration. 10. Design, construction, and system characterization, Journal of Membrane Science, 141 (1998) 183-195.

[153] H. Mallubhotla, M. Schmidt, K.H. Lee, G. Belfort, Flux enhancement during Dean vortex tubular membrane nanofiltration: 13. Effects of concentration and solute type, Journal of Membrane Science, 153 (1999) 259-269.

[154] S. Luque, H. Mallubhotla, G. Gehlert, R. Kuriyel, S. Dzengeleski, S. Pearl, G. Belfort, A new coiled hollow-fiber module design for enhanced microfiltration performance in biotechnology, Biotechnol. Bioeng., 65 (1999) 247-257.

[155] H. Chang, J.-A. Hsu, C.-L. Chang, C.-D. Ho, T.-W. Cheng, Simulation study of transfer characteristics for spacer-filled membrane distillation desalination modules, Applied Energy, (2015).

[156] M. Shakaib, S. Hasani, I. Ahmed, R.M. Yunus, A CFD study on the effect of spacer orientation on temperature polarization in membrane distillation modules, Desalination, 284 (2012) 332-340.

[157] G.A. Fimbres-Weihs, D.E. Wiley, Review of 3D CFD modeling of flow and mass transfer in narrow spacer-filled channels in membrane modules, Chemical Engineering and Processing: Process Intensification, 49 (2010) 759-781.

[158] M. Shakaib, S. Hasani, M. Mahmood, CFD modeling for flow and mass transfer in spacerobstructed membrane feed channels, Journal of Membrane Science, 326 (2009) 270-284.

[159] Y.-L. Li, K.-L. Tung, M.-Y. Lu, S.-H. Huang, Mitigating the curvature effect of the spacer-filled channel in a spiral-wound membrane module, Journal of Membrane Science, 329 (2009) 106-118.

[160] S. Wardeh, H. Morvan, CFD simulations of flow and concentration polarization in spacerfilled channels for application to water desalination, Chemical Engineering Research and Design, 86 (2008) 1107-1116.

[161] M. Shakaib, S. Hasani, M. Mahmood, Study on the effects of spacer geometry in membrane feed channels using three-dimensional computational flow modeling, Journal of Membrane Science, 297 (2007) 74-89.

[162] J.L.C. Santos, V. Geraldes, S. Velizarov, J.G. Crespo, Investigation of flow patterns and mass transfer in membrane module channels filled with flow-aligned spacers using computational fluid dynamics (CFD), Journal of Membrane Science, 305 (2007) 103-117. [163] J. Vrouwenvelder, C. Picioreanu, J. Kruithof, M. Van Loosdrecht, Biofouling in spiral wound membrane systems: three-dimensional CFD model based evaluation of experimental data, Journal of Membrane Science, 346 (2010) 71-85. 
[164] E. Lyster, J. Au, R. Rallo, F. Giralt, Y. Cohen, Coupled 3-D hydrodynamics and mass transfer analysis of mineral scaling-induced flux decline in a laboratory plate-and-frame reverse osmosis membrane module, Journal of Membrane Science, 339 (2009) 39-48.

[165] P. Tiwari, S.P. Antal, A. Burgoyne, G. Belfort, M.Z. Podowski, Multifield computational fluid dynamics model of particulate flow in curved circular tubes, Theoretical and Computational Fluid Dynamics, 18 (2004) 205-220.

[166] G. Belfort, Fluid mechanics in membrane filtration: Recent developments, Journal of Membrane Science, 40 (1989) 123-147.

[167] W.M. Deen, Analysis of Transport Phenomena, Oxford University Press, 2012.

[168] G. Belfort, G.A. Guter, An experimental study of electrodialysis hydrodynamics, Desalination, 10 (1972) 221-262.

[169] G. Fimbres-Weihs, D. Wiley, Numerical study of mass transfer in three-dimensional spacer-filled narrow channels with steady flow, Journal of Membrane Science, 306 (2007) 228243.

[170] A. Subramani, S. Kim, E.M. Hoek, Pressure, flow, and concentration profiles in open and spacer-filled membrane channels, Journal of Membrane Science, 277 (2006) 7-17.

[171] F. Altena, G. Belfort, Lateral migration of spherical particles in porous flow channels: application to membrane filtration, Chem. Eng. Sci., 39 (1984) 343-355.

[172] F. Altena, G. Belfort, J. Otis, F. Fiessinger, J. Rovel, J. Nicoletti, Particle motion in a laminar slit flow: A fundamental fouling study, Desalination, 47 (1983) 221-232.

[173] G. Belfort, P. Mikulasek, J.M. Pimbley, K.Y. Chung, Diagnosis of membrane fouling using a rotating annular filter. 2. Dilute particle suspensions of known particle size, Journal of Membrane Science, 77 (1993) 23-39.

[174] G. BELFORT, R.J. WEIGAND, J.T. MAHAR, Particulate membrane fouling and recent developments in fluid mechanics of dilute suspensions, in: ACS Symp. Ser., Oxford University Press, 1985, pp. 383-401.

[175] G. Green, G. Belfort, Fouling of ultrafiltration membranes: lateral migration and the particle trajectory model, Desalination, 35 (1980) 129-147.

[176] J. Otis, F. Altena, J. Mahar, G. Belfort, Measurements of single spherical particle trajectories with lateral migration in a slit with one porous wall under laminar flow conditions, Exp. Fluids, 4 (1986) 1-10.

[177] R. Weigand, F. Altena, G. Belfort, LATERAL MIGRATION OF SPHERICALPARTICLES IN LAMINAR POROUS TUBE FLOWS-APPLICATION TO MEMBRANE FILTRATION, Physicochemical Hydrodynamics, 6 (1985) 393-413.

[178] G.L. Baruah, A. Venkiteshwaran, G. Belfort, Global model for optimizing crossflow microfiltration and ultrafiltration processes: A new predictive and design tool, Biotechnology Progress, 21 (2005) 1013-1025.

[179] W. Xu, S. Chellam, Initial Stages of Bacterial Fouling during Dead-End Microfiltration $<$ sup $>\uparrow</$ sup $>$, Environmental Science \& Technology, 39 (2005) 6470-6476.

[180] J. Hermia, Constant pressure blocking filtration law application to powder-law nonNewtonian fluid, Trans. Inst. Chem. Eng., 60 (1982) 183-187.

[181] M. Taniguchi, J.E. Kilduff, G. Belfort, Modes of natural organic matter fouling during ultrafiltration, Environmental Science \& Technology, 37 (2003) 1676-1683.

[182] A.L. Zydney, L.J. Zeman, Microfiltration and Ultrafiltration, New York: Marcel Dekker, 1996. 
[183] R.W. Field, D. Wu, J.A. Howell, B.B. Gupta, CRITICAL FLUX CONCEPT FOR MICROFILTRATION FOULING, JOURNAL OF MEMBRANE SCIENCE, 100 (1995) 259272.

[184] P. Bacchin, P. Aimar, R.W. Field, Critical and sustainable fluxes: Theory, experiments and applications, JOURNAL OF MEMBRANE SCIENCE, 281 (2006) 42-69.

[185] C.C. Ho, A.L. Zydney, A combined pore blockage and cake filtration model for protein fouling during microfiltration, Journal of Colloid and Interface Science, 232 (2000) 389-399. [186] C. Duclos-Orsello, W.Y. Li, C.C. Ho, A three mechanism model to describe fouling of microfiltration membranes, JOURNAL OF MEMBRANE SCIENCE, 280 (2006) 856-866. [187] G. Bolton, D. LaCasse, R. Kuriyel, Combined models of membrane fouling: Development and application to microfiltration and ultrafiltration of biological fluids, Journal of Membrane Science, 277 (2006) 75-84.

[188] C.C. Ho, A.L. Zydney, Transmembrane pressure profiles during constant flux. microfiltration of bovine serum albumin, JOURNAL OF MEMBRANE SCIENCE, 209 (2002) 363-377.

[189] S. Chellam, N.G. Cogan, Colloidal and bacterial fouling during constant flux microfiltration: Comparison of classical blocking laws with a unified model combining pore blocking and EPS secretion, JOURNAL OF MEMBRANE SCIENCE, 382 (2011) 148-157. [190] S. Chellam, W.D. Xu, Blocking laws analysis of dead-end constant flux microfiltration of compressible cakes, Journal of Colloid and Interface Science, 301 (2006) 248-257.

[191] N.G. Cogan, S. Chellam, Incorporating pore blocking, cake filtration, and EPS production in a model for constant pressure bacterial fouling during dead-end microfiltration, Journal of Membrane Science, 345 (2009) 81-89.

[192] C.S. Laspidou, A. Kungolos, P. Samaras, Cellular-automata and individual-based approaches for the modeling of biofilm structures: Pros and cons, Desalination, 250 (2010) 390394.

[193] C.S. Laspidou, L.A. Spyrou, N. Aravas, B.E. Rittmann, Material modeling of biofilm mechanical properties, Math. Biosci., 251 (2014) 11-15.

[194] A.I. Radu, J.S. Vrouwenvelder, M.C.M. van Loosdrecht, C. Picioreanu, Modeling the effect of biofilm formation on reverse osmosis performance: Flux, feed channel pressure drop and solute passage, Journal of Membrane Science, 365 (2010) 1-15.

[195] A.I. Radu, J.S. Vrouwenvelder, M.C.M. van Loosdrecht, C. Picioreanu, Effect of flow velocity, substrate concentration and hydraulic cleaning on biofouling of reverse osmosis feed channels, Chemical Engineering Journal, 188 (2012) 30-39.

[196] J.S. Vrouwenvelder, C. Picioreanu, J.C. Kruithof, M.C.M. van Loosdrecht, Biofouling in spiral wound membrane systems: Three-dimensional CFD model based evaluation of experimental data, Journal of Membrane Science, 346 (2010) 71-85.

[197] A.I. Radu, L. Bergwerff, M.C.M. van Loosdrecht, C. Picioreanu, Combined biofouling and scaling in membrane feed channels: a new modeling approach, Biofouling, 31 (2015) 83-100. [198] L. Birnhack, N. Voutchkov, O. Lahav, Fundamental chemistry and engineering aspects of post-treatment processes for desalinated water-A review, Desalination, 273 (2011) 6-22.

[199] N. Delion, G. Mauguin, P. Corsin, Importance and impact of post treatments on design and operation of SWRO plants, Desalination, 165 (2004) 323-334.

[200] F.H. Kiang, W.W.L. Yong, D.D. Ratnayaka, The Singapore solutions, Civil Engineering, 77 (2007) 62-69. 
[201] W.H. Organization, Safe Drinking-water from Desalination, in, World Health Organization, Geneva, Switzerland, 2011.

[202] A. Withers, Options for recarbonation, remineralisation and disinfection for desalination plants, Desalination, 179 (2005) 11-24.

[203] S.J.P.-W. Duranceau, R.J.; Douglas, S.A.; Peña-Holt, N.; Watson, I.C. , Post-Treatment Stabilization of Desalinated Water, in, Denver, CO, 2011.

[204] S.A. Imran, J.D. Dietz, G. Mutoti, J.S. Taylor, A.A. Randall, C.D. Cooper, Red water release in drinking water distribution systems, Journal American Water Works Association, 97 (2005) 93-100.

[205] T.D. Prasad, E. Danso-Amoako, Influence of Chemical and Biological Parameters on Iron and Manganese Accumulation in Water Distribution Networks, Procedia Engineering, 70 (2014) 1353-1361.

[206] S.o. Israel, Public Health Regulations 2013, the Sanitary Quality of Drinking Water and Drinking Water Facilities, in: D.o.E. Health (Ed.), 2013.

[207] H. Sontheimer, W. Kolle, V.L. Snoeyink, THE SIDERITE MODEL OF THE FORMATION OF CORROSION-RESISTANT SCALES, Journal American Water Works Association, 73 (1981) 572-579.

[208] O. Lahav, L. Birnhack, Quality criteria for desalinated water following post-treatment, Desalination, 207 (2007) 286-303.

[209] L.S. McNeill, M. Edwards, Iron pipe corrosion in distribution systems, Journal American Water Works Association, 93 (2001) 88-+.

[210] S.M. Lesch, D.L. Suarez, A Short Note on Calculating the Adjusted SAR Index, Transactions of the Asabe, 52 (2009) 493-496.

[211] M. Edwards, L.S. McNeill, Effect of phosphate inhibitors on lead release from pipes, Journal American Water Works Association, 94 (2002) 79. 